\title{
Likely locations of sea turtle stranding mortality using experimentally-calibrated, time and space-specific drift models
}

\author{
Bianca Silva Santos \\ College of William and Mary - Virginia Institute of Marine Science, bianca.santos1128@gmail.com
}

Marjorie A.M. Friedrichs

Virginia Institute of Marine Science, marjy@vims.edu

Sarah A. Rose

Susan G. Barco

Virginia Aquarium \& Marine Science Center

David Michael Kaplan

Virginia Institute of Marine Science

Follow this and additional works at: https://scholarworks.wm.edu/articles

Part of the Environmental Monitoring Commons, and the Zoology Commons

\section{Recommended Citation}

Santos, Bianca Silva; Friedrichs, Marjorie A.M.; Rose, Sarah A.; Barco, Susan G.; and Kaplan, David Michael, "Likely locations of sea turtle stranding mortality using experimentally-calibrated, time and space-specific drift models" (2018). Articles. 75.

https://scholarworks.wm.edu/articles/75

This Article is brought to you for free and open access by W\&M ScholarWorks. It has been accepted for inclusion in Articles by an authorized administrator of W\&M ScholarWorks. For more information, please contact scholarworks@wm.edu. 
1 Likely locations of sea turtle stranding

2 mortality using experimentally-calibrated,

3 time and space-specific drift models

4

5 Bianca S. Santos ${ }^{1 a^{*}}$, Marjorie A.M. Friedrichs ${ }^{1 b}$, Sarah A. Rose $e^{2 c}$, Susan G. Barco ${ }^{2 d}$, David M.

$6 \quad K_{a p l a n}^{1 f \Phi}$

7 1. Virginia Institute of Marine Science, College of William \& Mary, Gloucester Point, VA

$8 \quad 23062$

9 2. Virginia Aquarium \& Marine Science Center, Virginia Beach, VA 23451

10

$11{ }^{\Phi}$ Current affiliation: Institut de Recherche pour le Developpement (IRD), MARBEC (Univ.

12 Montpellier, CNRS, Ifremer, IRD), Sète, France

13

14 Author email addresses: (a) bianca.santos1128@gmail.com; (b) marjy@ vims.edu; (c)

15 sarose@ virginiaaquarium.com; (d) sgbarco@virginiaaquarium.com; (f) dmk@ vims.edu

16 * Corresponding author: bianca.santos1128@ gmail.com; Phone: 1-908-448-6601 


\section{Abstract}

Sea turtle stranding events provide an opportunity to study drivers of mortality, but

19 causes of strandings are poorly understood. A general turtle carcass oceanographic drift model

20 was developed to estimate likely mortality locations from coastal sea turtle stranding records.

21 Key model advancements include realistic direct wind forcing on carcasses, temperature driven

22 carcass decomposition and the development of mortality location predictions for individual

23 strandings. We applied this model to 2009-2014 stranding events within the Chesapeake Bay,

24 Virginia. Predicted origin of vessel strike strandings were compared to commercial vessel data,

25 and potential hazardous turtle-vessel interactions were identified in the southeastern Bay and

26 James River. Commercial fishing activity of gear types with known sea turtle interactions were

27 compared to predicted mortality locations for stranded turtles with suggested fisheries-induced

28 mortality. Probable mortality locations for these strandings varied seasonally, with two distinct

29 areas in the southwest and southeast portions of the lower Bay. Spatial overlap was noted

30 between potential mortality locations and gillnet, seine, pot, and pound net fisheries, providing

31 important information for focusing future research on mitigating conflict between sea turtles and

32 human activities. Our ability to quantitatively assess spatial and temporal overlap between sea

33 turtle mortality and human uses of the habitat were hindered by the low resolution of human use

34 datasets, especially those for recreational vessel and commercial fishing gear distributions. This

35 study highlights the importance of addressing these data gaps and provides a meaningful

36 conservation tool that can be applied to stranding data of sea turtles and other marine megafauna

37 worldwide. 
38 Keywords: Sea turtle strandings; Sea turtle mortality; Chesapeake Bay; Drift simulations;

39 Fisheries and vessel interactions; Endangered species; Marine conservation; Protected species

40 management 


\section{Introduction}

Many of the world's marine megafauna are highly threatened by a mixture of

43 anthropogenic pressures (Learmonth et al. 2006, Crain et al. 2009, Wallace et al. 2013, Lewison

44 et al. 2014) and natural threats (George 1997, Gulland and Hall 2007, Heithaus et al. 2008).

45 Among these species are marine sea turtles, of which six out of the seven species worldwide are

46 listed on the IUCN Red List of Threatened Species (http://www.redlist.org). For sea turtles and

47 other marine megafauna, a better understanding of the impacts of anthropogenic activities on

48 these species is essential to assessing risk of population extinction and identifying effective

49 conservation strategies. Sea turtle strandings provide an important opportunity to study turtle

50 mortality and identify threats for future mitigation and conservation actions, however,

51 identifying potential causes of mortality of stranded sea turtles can be extremely challenging due

52 to state of carcass decomposition and the lack of physical evidence of the cause of mortality

53 (Hart et al. 2006, Koch et al. 2013). In particular, interactions with some fishing gears often do

54 not leave marks on turtles, due to a combination of gear type and sea turtle anatomy (i.e. hard

55 parts), thus solely using injuries noted at time of stranding to attribute cause of death has been

56 suggested to grossly underestimate fisheries-induced mortality (Barco et al. 2016). Fishing

57 activity has been noted as a large driver of anthropogenic sea turtle mortality worldwide, with

58 lethal interactions documented in gear types including longlines, trawls, gillnets, pound nets,

59 dredges, seines and pots (Lewison et al. 2004, Zollett 2009, Wallace et al. 2010, Finkbeiner et al.

60 2011). Despite the current vulnerability of sea turtle species and known interactions with

61 recreational and commercial fishing gear, as well as commercial and recreational vessel traffic,

62 management actions are still frequently hindered by lack of specific information on where and

63 when human-turtle interactions occur. 
The Chesapeake Bay (Bay) and its surrounding coastal waters are critical foraging and

65 developmental habitats for thousands of sea turtles that use these waters seasonally (Musick and

66 Limpus 1997, Mansfield 2006). However, hundreds of deceased turtles are found stranded on

67 Virginia's coastline each year. The Virginia Sea Turtle Stranding and Salvage Network (VAQS),

68 currently led by the Virginia Aquarium \& Marine Science Center, has been responding to

69 strandings throughout the state since the 1970s, documenting 100-300 events annually in the past

70 decade (Swingle et al. 2016). Strandings are observed throughout the year, although the majority

71 of annual strandings usually occur during a strong spring peak in May and June when turtles are

72 first entering the Bay (Lutcavage and Musick 1985, Coles 1999). Mortality continues at a

73 relatively high level throughout the summer, followed in some years by a small fall peak in

74 strandings associated with turtles migrating out of the Bay to avoid cold winter temperatures

75 (Mansfield et al. 2009). Juvenile loggerheads are the most commonly reported sea turtles found

76 within Virginia's waters, followed by the critically endangered Kemp's ridley

77 (http://www.redlist.org) (Lutcavage and Musick 1985, Coles 1999, Barco and Swingle 2014).

78 Importantly, Virginia's waters provide crucial habitats for loggerheads from several different

79 western Atlantic distinct population units (Conant et al. 2009, Mansfield et al. 2009, NMFS

80 2011, Ceriani et al. 2017), thus local mortality could lead to detrimental impacts among multiple

81 loggerhead subpopulations (Mansfield et al. 2009). . Strandings likely represent a minimal

82 measure of actual at-sea mortality, with some studies in open ocean environments estimating

83 stranding events to represent only 10-20\% of total deaths (Epperly et al. 1996, Hart et al. 2006;

84 note, however, that these stranding percentages may be higher in the semi-enclosed Bay). Given

85 the important role the Bay plays in regional sea turtle life cycles, detailed information on the 
86 times, places and causes of mortality are essential to maintaining and increasing these

87 populations.

When stranded sea turtles are recovered as fresh dead carcasses, cause of death can often

89 be determined by conducting a thorough necropsy and submitting tissues to a veterinary

90 pathologist for histopathology. Barco et al. (2016) summarized cause of death for 70 fresh

91 carcasses recovered in Virginia and North Carolina from 2004-2013. Nearly half of the turtles

$92(n=31 ; 44 \%)$ died from acute vessel $(n=15)$ or fishery interaction $(n=16)$ and most of these were

93 apparently healthy prior to death with no significant pathology and good body condition,

94 suggesting they were not already compromised in any way prior to mortality (Barco et al. 2016).

95 Of those turtles that were categorized as drowning from fishery interaction, few, if any, lesions

96 were present on the carcasses (Barco et al. 2016), which is similar to some fishery interaction

97 cases in cetaceans (Moore et al. 2013). This lack of injuries has importance for the majority of

98 dead stranded sea turtles observed in Virginia, which are in a moderate to advanced state of

99 decomposition at time of discovery. Though some causes of death, such as drowning due to

100 underwater entrapment in fishing gear, are impossible to definitively assess in these more

101 extensively decomposed cases, they often share several of the characteristics of fishery

102 interactions, such as a lack of lesions or obvious pathology. Collectively, these results suggest

103 that vessel and fishery interactions are important sources of human-induced mortality in the Bay,

104 but more information is needed on the locations of mortality to help pinpoint the gears or vessels

105 likely responsible. Turtles in this region have been documented caught or entangled in pound net

106 leader hedging, gillnets, trawl nets, crab pot lines and whelk pot lines (Bellmund et al. 1987,

107 Keinath et al. 1987, Mansfield et al. 2001, Barco et al. 2016). Although there is no concrete

108 evidence of the Chesapeake Bay's menhaden purse seine fishery causing sea turtle mortality, 
109 other purse seine fisheries in the region are known to kill turtles (Silva 1996) and there is no

110 state-run observer program for this and many other fisheries in the Bay (Barco et al. 2015).

111 Narrowing down this list of potential causes for sea turtle mortality in the Bay to the most

112 prevalent causes, locations and time periods is essential to developing targeted conservation

113 strategies for these threatened species.

114 Mitigating sea turtle mortality (especially when fishery observer data are limited)

115 requires investigation into the location of mortality in order to assess potential causal

116 mechanisms and identify hotspots for negative human-turtle interactions. After sea turtles die,

117 their bodies sink until decomposition gases causes the body to bloat and float to the surface (if

118 not entangled). Partially submerged and acting as drifting objects, carcasses are transported by

119 winds and currents. Landfall may occur if conditions are favorable to onshore transport and the

120 turtle carcass does not decompose and sink before reaching a coastline. Santos et al. (2018)

121 found that sea turtle carcass drift time is highly dependent on water temperature due to

122 decomposition rates and that winds make an important contribution to the net transport of turtle

123 carcasses. Oceanographic modeling and drift studies have been used in the past to understand

124 mechanisms for larval release and dispersal (Garavelli et al. 2012), as well as to predict

125 trajectories of drifting human bodies (Carniel et al. 2002) and cetacean carcasses (Peltier et al.

126 2012). A limited number of recent studies have applied this approach to sea turtle carcasses in

127 other geographic regions (Hart et al. 2006, Nero et al. 2013, Koch et al. 2013), providing

128 valuable insight on stranding causes and likelihood. Santos et al. (2018) conducted preliminary

129 investigations into sea turtle carcass drift patterns within the Chesapeake Bay area specifically,

130 however strandings were not assessed at the individual level, with potential mortality hotspots 
131 based on fairly general areas of historically high stranding rates. Furthermore, only stranding

132 locations during June, the peak month of sea turtle strandings in Virginia, were assessed.

133 In this study, we construct an oceanographic drift model for the lower Chesapeake Bay to

134 predict the probable location of mortality for individual coastal sea turtle strandings in Virginia

135 based on the location of stranding, state of carcass decomposition and environmental conditions.

136 We simulated the drift patterns of dead turtles prior to stranding and identified likely locations of

137 sea turtle mortality using the starting points of particle trajectories arriving at the stranding

138 location at the correct time and decomposition state. Empirical results from Santos et al. (2018)

139 were used in the drift model to parameterize the probable oceanic drift time as a function of

140 temperature and the impact of direct wind forcing on carcass drift. We applied this adjusted

141 model to individual sea turtle stranding observations in coastal areas of Virginia and most

142 probable mortality locations within the region were identified for specific classes of strandings

143 with similar characteristics (e.g., probable cause of death, state of carcass decomposition).

144 Overall, this study provides a basis for quantitative and qualitative comparisons with

145 spatial distributions of potential causes of sea turtle mortality in the Bay. Our previous work

146 parameterized the characteristics of drifting sea turtle carcasses and found general areas of likely

147 sea turtle mortality in the Bay (Santos et al. 2018). Here, we build upon that preliminary study to

148 predict the trajectories and mortality locations of individual strandings, aggregating results over

149 many events and making comparisons with available information on potential causal

150 mechanisms. The model constructed in this paper also includes a number of methodological

151 improvements to the methods outlined in Santos et al. (2018), including the incorporation of

152 winds, currents, temperature and carcass condition on carcass drift, that can be applied to 
153 stranding data for sea turtles and other marine megafauna around the globe to better understand

154 and mitigate mortality events.

\section{2. Material and Methods}

A model simulating the drift of dead sea turtles prior to stranding was developed using

157 the offline Lagrangian drift simulation tool Ichthyop version 3.3 (Lett et al. 2008, Santos et al.

158 2018). The model was configured to release 20,000 pseudo-particles (i.e. simulated particles)

159 throughout the oceanographic domain every three hours and run forward in time based on

160 transport estimates from a wind reanalysis product and an ocean circulation model (Fig. 1a).

161 Pseudo-particles arriving at stranding locations at the appropriate time (i.e. probable date of

162 landfall based on reported stranding date) and having a desired set of conditions (see below)

163 were considered to represent potential turtle carcass drift trajectories. The release points for

164 many such trajectories were aggregated to create a probability distribution representing likely

165 mortality locations of stranding events.

166 Water circulation information was derived from an implementation of the Regional

167 Ocean Modeling System (ChesROMS; version 3.6) for the Chesapeake Bay area (Feng et al.

168 2015, Irby et al. 2016, 2017, Luettich et al. 2017, Moriarty 2017, Da 2018) and wind forcing was

169 obtained from the North American Regional Reanalysis (NARR) (Mesinger et al. 2006). The

170 horizontal grid cell size for ChesROMS and NARR varied over space, but was on average 1.7

$171 \mathrm{~km}$ and $32 \mathrm{~km}$, respectively. ChesROMS included tidal fluctuations and fresh water inputs from

172 major rivers in the region. ChesROMS,NARR data and Ichthyop output timesteps were all 3

173 hours. Ichthyop's internal timestep was set to 20 minutes.

174 The amount of direct wind forcing on the surface transport of turtle carcasses is estimated

175 to be $1-4 \%$ of wind speed (Nero et al. 2013, Santos et al. 2018). Wind forcing was thus added to 
176 the ChesROMS currents at $0 \%, 2 \%$ and $4 \%$ of wind speed to assess sensitivity of estimates to

177 wind forcing levels over the range of experimentally observed levels. Resulting particle

178 trajectories therefore represent the combined impacts of wind and currents on carcass

179 movements. When presenting model results, $2 \%$ wind forcing will be used unless otherwise

180 indicated because it is closest to experimentally observed values in Santos et al. (2018). A

181 comparison of drift trajectories from modelled pseudo-particles to experimentally-observed data

182 can be found in the supplement materials.

\subsection{Stranding data}

184 Sea turtle stranding data collected by VAQS during 2009-2014 were analyzed. Strandings

185 include dead and live animals, but the potential for active swimming of sick turtles found alive

186 can complicate the simulation of their movements. In this study, we focus only on deceased

187 individuals found washed ashore and refer to these as "stranded turtles" with the understanding

188 that we are excluding live turtle strandings. All stranding data were reviewed and each event was

189 consistently assigned a stranding date (date of report, not date of examination, if different),

190 carcass condition (at time of report, if available) and probable cause of death (based on gross

191 external and internal examinations). Carcass condition was determined on a qualitative scale of 1

192 (freshly dead) to 5 (bones) as per the National Oceanic and Atmospheric Administration's Sea

193 Turtle Stranding and Salvage Network guidelines

194 (https://www.sefsc.noaa.gov/species/turtles/strandings.htm). Causes of death included: vessel

195 strike, disease, cold-stunning, pollution/debris, entanglement, no apparent injuries and unable to

196 assess. When moderately and severely decomposed turtles were examined, but no injury or

197 disease was observed, the probable cause of death was listed as "no apparent injuries". Thus,

198 turtle carcasses classified as "no apparent injuries" includes turtles that appear to have been 
199 healthy prior to death. The category "unable to assess" was comprised of stranding events with

200 insufficient information (i.e. evaluated by an unqualified observer, necropsy was not performed,

201 etc.) to assign a probable cause of death category.

202 The developed model depends on the assumptions that stranded turtles died at-sea, were

203 able to float freely (i.e. not entangled), and the stranding event was reported and documented

204 shortly after beaching on land. Carcass decomposition state at time of discovery on the beach

205 was recorded on a condition code scale from 1 to 5 , with lower condition codes indicating a

206 "fresher" carcass that likely died more recently, and, thus, drifted for a shorter amount of time.

207 Based on experimental results that turtles are positively buoyant and capable of drifting only

208 until code 3 (Santos et al. 2018), stranding events with condition codes 4-5 were omitted from

209 analyses as beach time to decay to these states was difficult to determine and open ended. Thus,

210 analysis of stranding data was limited to turtles within the model domain that were classified as

211 condition codes 1-3 $(n=1023)$.

212 We also limited analyses to strandings documented on the coastlines within identified

213 regions of relatively high human population densities, with the assumption that strandings in

214 these areas were discovered and reported in a timely manner $(n=751 ; 73 \%)$. This included

215 stranding events documented along the coasts of Virginia Beach, Norfolk, and bayside

216 Northampton County (Fig. 1b). Virginia Beach and Norfolk are highly inhabited areas and

217 popular summer vacation spots, where water front areas are frequently visited in the warmer

218 months (Virginia Tourism Corporation 2015). Strandings in these areas were assumed to be

219 observed and reported by a member of the public at least every 24-hours. Although Northampton

220 has a lower population density, visitors frequently walk the beaches during the popular summer

221 months, particularly along the southern bayside of the peninsula where most strandings were 
222 reported. The ocean-facing coastline of Northampton County is made up of uninhabited barrier

223 islands that are difficult to access, thus strandings in these areas were omitted from analyses

$224(\mathrm{n}=22 ; 2.2 \%)$. We also excluded strandings located in small tributaries and other waterways, for

225 these water areas were not well represented in the oceanographic model and the assumption of

226 observation within 24-hours likely did not hold true $(\mathrm{n}=20 ; 2.0 \%)$.

227 From the remaining subset of strandings, we focused on those occurring during the

228 spring, summer and fall (May-October/November) $(n=651 ; 87 \%)$. Due to lethal water

229 temperatures, turtles are not typically present in the Bay during the winter when temperatures fall

230 below $18^{\circ} \mathrm{C}$ (Lutcavage and Musick 1985, Coles 1999). Turtles that strand during this non-

231 residency period likely either died long before being observed or drifted over long times and

232 distances, both of which complicate estimating their probable mortality locations.

\subsection{Criteria for a "successful" stranded particle}

234 Three basic conditions were established to determine which particle trajectories

235 potentially correspond to the drift pathways of a stranded turtle, including: 1) arriving within the

236 stranding target area, 2) arriving within a 24-hour time period around the documented stranding

237 event, and 3) having the appropriate state of decomposition (Fig. 2).

238 A target zone was created around the geographic location of each stranding event.

239 Stranding coordinates were snapped to the coastline of the model domain and a target zone with

240 a water area of $28.3 \mathrm{~km}^{2}$ was created around each stranding location. This area is equal to the

241 area of a $3 \mathrm{~km}$ radius circle, but the actual offshore extent of the buffer around each stranding

242 location was varied so that the water area was constant across strandings after taking into

243 account differences in coastline morphology. Carcass drift simulations were run targeting these

244 specific individual target zones before and up to the date of the corresponding strandings. 
246 County were observed for turtle strandings once a day, ranging from approximately 6am to $6 \mathrm{pm}$

247 EST (local time) (Nero et al. 2013). Therefore, we assumed that the actual beaching event in

248 these areas could have occurred anytime from 6pm the night before to 6pm the day of the

249 reported stranding. This 24-hour duration was used as the stranding window for simulations,

250 with "competent" particles (described below) arriving in the stranding target zone during this

251 time period considered to have "successfully" stranded.

Particle tracking times were based on results of a recent sea-turtle carcass decomposition

253 study (Santos et al. 2018) that used modeled water temperatures along particle trajectories and

254 carcass condition codes to determine drift duration. Here, we limited turtle carcass drift duration

255 to the interval of positive buoyancy (i.e., after the turtle had bloated sufficiently to float to the

256 surface, but before decomposition released internal gases causing the carcass to sink again to the

257 bottom). Linear regressions were used on buoyancy and condition code results from Santos et al.

258 (2018) to determine the minimum and maximum duration a floating carcass spent in each

259 condition code at a given water temperature (Fig. 3). As turtles in condition 1 were not observed

260 buoyant in the study, condition code 1 turtles were assigned a maximum drift duration of 1 day

261 (similar to Nero et al. 2013), and drift duration for turtles with condition codes 2 and 3 were

262 increased by 24 hours relative to raw results from Santos et al. (2018).

263 Each model pseudo-particle had a minimum and maximum drift time during which the

264 particle was considered to be buoyant and to have the observed condition code for the

265 corresponding stranding. If temperatures were constant over space and time, then the minimum

266 and maximum drift times would be given by the results from Santos et al. (2018) at fixed

267 temperature (Fig. 3; for example, at $20^{\circ} \mathrm{C}$, we would predict a code 3 turtle would have been 
268 drifting for approximately 7 to 12 days). However, as temperatures vary, the advancement of a

269 particle towards the minimum and maximum drift duration over a model timestep was assessed

270 as equal to the fraction of the minimum and maximum drift times that the timestep represents for

271 the temperature at the particle location. These fractions were cumulatively summed over

272 timesteps until the total fraction for minimum drift time was $>1$, but the total for maximum drift

273 time was $<1$. This defined a "competency" window for each particle trajectory during which the

274 carcass was considered to be of the appropriate decomposition state to strand. Particles were then

275 assessed to see if they were within the stranding target zone during this time interval.

276 Simulations were run targeting each stranding zone individually and starting points of

277 "successful" stranding particles were mapped on a $5 \mathrm{~km}$ x $5 \mathrm{~km}$ grid. For each stranding, a

278 relative particle density was calculated for each grid cell representing the estimated probability

279 that the turtle died in that grid cell. For each release event (occurring every 3 hours), the number

280 of particles released in each grid cell that successfully landed in the stranding zone at the

281 appropriate time was divided by the total number of particles released in that grid cell to get the

282 relative probability of "successful" stranding. These relative probabilities were then summed

283 over all release events for that stranding and the resulting sum for each grid cell was further

284 divided by the sum over all grid cells so that the total probability of mortality over all grid cells

285 for a given stranding event was 1.

$286 \quad 2.3$ Analyses

287 Probable mortality locations for individual stranding events were aggregated over the six288 year study period by time of year and/or stranding type to develop synthetic maps of recurrent 289 mortality locations. Probability maps for groups of strandings were added together and then the 290 total was divided by the number of strandings to obtain a final synthetic normalized probability 
291 map for the group of strandings. Stranding events having a low number of particles that met all

292 the stranding criteria (defined as $<100$ particles in total) were omitted from these syntheses to

293 prevent skewing results in specific cases where fine-scale coastal movements may not have been

294 accurately represented in the model ( $\mathrm{n}=13$ for $0 \%$ wind forcing, $\mathrm{n}=23$ for $2 \%$, and $\mathrm{n}=48$ for $4 \%$ )

295 Strandings occurring during the spring peak in May and June and throughout the rest of

296 the summer stranding period were analyzed separately to investigate potential differences in

297 mortality locations and sources between these two time periods. The timing of the spring peak

298 period was independently assessed for each year by plotting the number of strandings per week

299 and visually identifying the sharp peak in strandings in May, indicating onset, followed by a

300 sharp drop off during June, representing the end of the peak period approximately 3-5 weeks

301 later. The duration of the remaining summer and early fall foraging season was defined in a

302 similar manner to encompass the time period after the end of the spring peak until the frequency

303 of stranding events greatly diminished around October or November. This period varied by year

304 from 19 to 23 weeks, occasionally including an irregular second fall peak in strandings. The fall

305 peak was not separately analyzed as it was hard to consistently define across years and

306 represented a relatively small total number of strandings (Fig. A.1).

307 Probability maps of turtle mortality locations were further categorized by probable cause

308 of death as determined by necropsy results and external visual observations of the stranded

309 turtles. Categories examined included vessel strike ( $\mathrm{n}=250 ; 38 \%)$, no apparent injuries $(\mathrm{n}=163$;

$31025 \%)$, and unable to assess $(n=199 ; 31 \%)$. The remaining $6 \%$ of strandings $(n=39)$ included

311 carcasses with death attributed to disease, cold-stunning, pollution/debris or entanglement. Due

312 to low sample size and diversity surrounding potential causes of mortality, these strandings were

313 excluded from analyses. Combining the two stranding "seasons" (spring peak and remainder of 
314 the summer/fall) and these three probable cause of death categories yielded a total of six possible

315 synthetic maps, of which only five were produced because there were no code 1 strandings that

316 met all our criteria during the non-peak stranding period in the "unable to assess" category.

317 Spatial overlap between predicted mortality locations of vessel strike turtles and U.S.

318 Coast Guard shipping lane data were evaluated to assess model validity and identify areas of

319 high mortality due to vessel traffic. Vessel location data from the Automatic Identification

320 System (AIS) for non-federal vessels over $65 \mathrm{ft}$ in length were obtained during the 2009-2014

321 time period at 1-minute intervals (https://marinecadastre.gov/ais/). We limited data to vessels

322 traveling faster than $4 \mathrm{~km} / \mathrm{hr}$, the reported speed at which turtles cannot actively avoid being

323 struck by watercraft (Hazel et al. 2007). Vessel density was computed for each year-month strata

324 and rasterized on the $5 \mathrm{~km} \times 5 \mathrm{~km}$ grid used to predict turtle mortality. As AIS position data is

325 limited to larger, non-federal vessels, it does not include many vessels that could be responsible

326 for boat strikes. Therefore, we chose to use a wider, monthly temporal resolution to better

327 capture general boat traffic in the bay. Relative probability of vessel activity for each year-month

328 was computed by dividing the number of AIS data points in each grid cell by the total number of

329 points over all grid cells for that strata. The predicted mortality location map for each stranding

330 record was multiplied cell-by-cell with the corresponding year-month relative vessel activity

331 layer, resulting in a joint probability distribution map, with each grid cell representing the

332 probability that both vessel activity occurred and the turtle died in that location. This joint

333 probability map was summed over all grid cells to develop a single indicator of the overlap

334 between predicted mortality locations and AIS-tracked vessel activity. AIS data from September

335 to November 2014 were incomplete, so vessel strike turtles that stranded during this time period

336 were omitted from analyses $(n=18)$. 
In order to assess whether or not the model was successfully predicting the mortality

338 locations of known vessel strike stranding records, a Monte Carlo randomization analysis was

339 performed to compare overlap between vessel activity and the predicted mortality locations of

340 these strandings with the overlap for a randomized mortality location probability map. For each

341 individual stranding event, the model-predicted probability map was randomly reshuffled over

342 the area of all possible mortality locations of turtles for the corresponding year, resulting in a

343 randomly distributed probability map. Similar to the model predicted maps, the randomly

344 generated mortality grids were multiplied by the vessel activity map and summed over all grid

345 cells to obtain an indicator of the overlap between these data sets. This process was repeated

3465,000 times for each individual stranding event. A pseudo-p-value was calculated as the fraction

347 of these 5,000 trails for which the model predicted map had a lower overlap with vessel activity

348 than the randomly distributed null maps. These pseudo-p-values were then aggregated by

349 stranding condition code and plotted as a density function.

350 Predicted mortality locations for stranding records with probable cause of death classified

351 as "unable to assess" and "no apparent injury" were identified and spatially compared to data on

352 anthropogenic activities. Total harvest for different gear types throughout the Chesapeake Bay

353 were obtained from the Virginia Marine Resource Commission (VMRC) for the 6-year study

354 period. Spatio-temporal maps of fishing effort are not generally available for fisheries in the

355 Chesapeake Bay, so instead we used total harvest as a rough indicator of extraction intensity in

356 general regions. Due to privacy and data resolution issues, harvest was only available as an

357 aggregate over the entire study period and for individual "waterways", marine areas defined by

358 VMRC and used for harvest reporting by fishermen (Fig. A.2). Gear types that are thought to

359 pose particular threats to sea turtle, including gillnets, haul seines, and pots and traps were subset 
360 and mapped by waterway. To ensure confidentially in cases where the number of harvesters per

361 gear-waterway combination was low, results for certain water areas were grouped together by

362 "water system" (a larger area defined by VMRC to include multiple nearby waterways). In the

$36310 \%$ of instances where this occurred, total pounds harvested per gear-waterway strata was

364 estimated by dividing the gear-water system total among the number of waterway represented

365 within the grouping. Fine scale pound net and stake gillnets locations were obtained from the

366 VMRC website for 2017, the current license year at the time of the study

367 (https://webapps.mrc.virginia.gov/public/maps/chesapeakebay_map.php). Point locations were

368 extracted and plotted on the $5 \mathrm{~km}$ x $5 \mathrm{~km}$ grid by length of net per unit area. Although fine-scale

369 information on staked gillnets and pound nets locations were only available for 2017, these are

370 stationary, semi-permanent fishing gears that likely remain in the same general area over many

371 years. In addition, this point license location information matches relatively well with available

372 broader-scale information on aggregated 2009-2014 harvest (Fig. A.3). Therefore, the gridded

3732017 stake gillnet and pound net locations were deemed appropriate to use for comparisons with

374 the 2009-2014 data. Location of purse-seine sets by Omega Protein vessels from 2011-2013 were

375 obtained from the 2015 Atlantic Menhaden Stock Assessment Report (SEDAR 2015). Images of

376 set locations were georeferenced and digitized in ArcGIS, and presence/absence of purse seines

377 noted on a $5 \mathrm{~km} \times 5 \mathrm{~km}$ grid.

378 To assess changes in carcass drift duration throughout the stranding season, timespan and

379 distance from point of release to the first timestep for which all three stranding criteria were met

380 was recorded for each "successful" stranding particle for all stranding events. Given the

381 variability in drift criteria across condition code, we limited this analysis to strandings classified

382 as condition code 3 to observe trends at the maximum range (results for condition code 2 
383 strandings were qualitatively similar). Average drift times and distances per stranding were

384 binned by week of the year and averaged together over the 6-year study period.

385 3. Results

Possible drift time for strandings classified with condition codes 2 and 3 decreased with

387 warming water temperature (Fig. 3). The effect of temperature was found to be statistically

388 significant on the maximum drift time for code 2 turtles $\left(\mathrm{p}<0.001, \mathrm{R}^{2}=0.7495\right)$ as well as the

389 minimum $\left(\mathrm{p}<0.01, \mathrm{R}^{2}=0.7947\right)$ and maximum $\left(\mathrm{p}<0.001, \mathrm{R}^{2}=0.8932\right)$ drift times for code 3

390 turtles (Table 1).

$391 \quad$ Average drift times and straight-line distances for pseudo-particles successfully arriving

392 at condition code 3 stranding target zones decreased throughout the late spring (May-late June),

393 reached minimal values of $\sim 2-5$ days and $\sim 15-30 \mathrm{~km}$, respectively, during the summer months

394 (late June-late September) before increasing again in the fall (late September-November) (Fig.

395 4a-b). The minimum in both drift times and distances occurred in July, shortly after the spring

396 peak period. A significant relationship was noted between drift time and drift duration (Fig. 4c;

$\left.397 \mathrm{p}<0.001, \mathrm{R}^{2}=0.2746\right)$.

$398 \quad$ Although predicted mortality locations differed among probable cause of death

399 categories, as well as between spring peak and summer, non-peak stranding time periods, high

400 probability zones for mortality were consistently identified in areas within the main channel of

401 the lower Bay, as well as the James River which includes the port of Hampton Roads (Figs. 1c,

402 5-7). Mortality locations for strandings where vessel strike was the probable cause of stranding

403 were largely concentrated in the southwest portion of the Bay, while most probable locations for

404 strandings classified as having no apparent injuries or where responders were unable to assess

405 cause of stranding were generally more dispersed and also included areas in the southeast 
406 quadrant of the Bay. In all cases, mortality was less likely to occur in tributaries of the Bay, with

407 a notable exception of the James River.

$408 \quad 3.1$ Vessel strikes

$409 \quad$ Analyses of commercial vessel density data highlighted high vessel activity during 410 months with observed stranding data in the lower Chesapeake Bay, particularly along shipping

411 channels of bayside areas of Norfolk and Virginia Beach and within the lower James River (Fig.

412 5a). Overall predicted mortality locations of stranded sea turtles with evidence of vessel strike

413 were concentrated in the lower, southwest portion of the Chesapeake Bay (Fig. 5b). In particular,

414 high probability was noted near the mouth of the James River and the bayside coast of Norfolk in

415 the vicinity of both the commercial and military ports. Mortality was also moderate to high near

416 the bayside coast of Northampton County, near the mouth of the Bay, and in the northern

417 oceanic-coast of Virginia Beach. A combined probability map depicting overlap of both vessel

418 activity and probable vessel strike turtle mortality was very heavily weighted towards the

419 immediate vicinity of the Lynnhaven Inlet and Elizabeth River (Figs. 1c, 5c).

420 Results from the Monte Carlo randomization analyses showed a strong distribution of

421 low p-values across all condition codes, indicating that the model was doing considerably better

422 than random at predicting vessel-strike mortality event locations (Fig. 8). Actual predicted

423 mortality locations derived from the model were better $(\mathrm{p}<0.05)$ at predicting overlap with vessel

424 activity than expected by random chance for approximately $67 \%$ of code 1 turtles (4 out of 6

425 strandings), $73 \%$ of code 2 turtles (115 out of 156), and $46 \%$ of code 3 turtles (30 out of 71 ).

\section{$426 \quad 3.2$ No apparent injuries and unable to assess}

427 Predicted mortality locations for strandings classified as "no apparent injuries" or "unable 428 to assess" generally occurred throughout the lower Bay, with noted differences in probable 
mortality locations between the spring peak in strandings and the rest of the summer stranding

430 period (Figs. 6-7). Turtles classified as condition code 1 originated in nearshore areas relatively

431 close to stranding locations. Although sample size was low, elevated mortality probability for

432 these strandings were noted near the bayside coasts of Virginia Beach and Northampton. As

433 cause of death was easier to determine in fresher carcasses, there were no documented code 1

434 "unable to assess" strandings that met all stranding data conditions during the non-peak stranding

435 period. During the spring peak, predicted mortality locations for turtles classified as either

436 condition code 2 or 3 were heavily concentrated at the mouth of the James River and along the

437 Northampton County lower bayside coast. Additionally, there was a strong likelihood of

438 mortality near Hampton County (Fig. 1c) for condition code 3 turtles classified as "no apparent

439 injuries" that was not present in any of the other images, with elevated mortality probability

440 concentrated in a region spanning across the lower main-stem of the Bay. Non-peak stranding

441 mortality locations were generally more diffuse in space, with high probability near the bayside

442 coast of Northampton County.

\section{$443 \quad 3.3$ Wind forcing}

444 Although major areas of predicted mortality remained the same between $0 \%, 2 \%$, and $4 \%$

445 of wind forcing on carcass drift, increasing winds had a general tendency towards increasing the

446 spread and geographic range of predicted mortality locations (Fig. 9). For example, the three

447 concentrated regions of high predicted mortality locations for turtles classified as condition code

4482 with no apparent injuries during the spring peak, including, the James River, the southern

449 bayside coast of Northampton County, and the Virginia Beach Oceanfront, were most obvious

450 with $0 \%$ wind forcing and became slightly smaller at $2 \%$ and $4 \%$ (Fig. 9). However, an area of

451 high mortality remained constant within the lower southwest portion of the Bay and the James 
452 River across all three wind speed percentages. The high likelihood of mortality occurring in this

453 area across all wind conditions was highlighted in a map depicting the mean of these three

454 probability images (Fig. 9d).

\section{$455 \quad 3.4$ Fishing data}

456 Focusing primarily on those gears and fisheries that were most active in the lower Bay

457 and James River and were predicted to be associated with turtle mortality that could lead to

458 strandings (Figs. 6-7), we found that areas of activity of sink/anchor gillnets (as well as drift

459 gillnet to a lesser extent; Fig. 10a-b), haul seines (Fig. 10c), crab pots and traps (Fig. 10e), and

460 the purse-seine fishery for Menhaden (Fig. 11a) overlapped extensively with areas of predicted

461 sea turtle mortality. Nevertheless, the limited spatial and temporal resolution of the data made

462 quantitative assessments of overlap impossible. Of the fixed gears, only pound net locations

463 (Figs. 11c) corresponded with some of the predicted turtle mortality locations along the bayside

464 of Northampton County. Whelk pots and traps (Fig. 10d) and sink gillnets (Fig. 11b) were

465 located in regions of the upper Bay or oceanic waters outside the Bay, areas that generally did 466 not greatly overlap with predicted turtle mortality locations.

\section{4. Discussion}

In this study, we developed the first model for predicting mortality locations of individual

469 stranded sea turtles in Virginia, USA, using a methodology that is widely applicable to stranding

470 data for sea turtles and other megafauna around the world. The novel approach used in our model

471 incorporated wind, current, and temperature effects on carcass drift to stranding locations. We

472 identified probable mortality locations for different cause of stranding categories for sea turtles

473 in the Chesapeake Bay, making comparisons between high-probability areas with available

474 information on fisheries activity and commercial vessel traffic. Identified hotspots during the 
475 peak (May-June) and non-peak (July-October/November) stranding season suggest that much of

476 the mortality leading to sea turtle strandings in the lower Chesapeake Bay occurs in two distinct

477 regions: 1) near the vicinity of the James River and 2) near the lower bayside coast of

478 Northampton County. These results are in line with those of Santos et al. (2018), who identified

479 probable mortality hotspots during the peak month of strandings (June) within the lower Bay.

$480 \quad 4.1$ Vessel strikes

Combined probability maps of vessel density and predicted mortality locations for turtle

482 likely to have stranded due to a vessel strike suggests that watercraft interactions leading to

483 mortality occur primarily in the lower Chesapeake Bay just north of Virginia Beach in the

484 vicinity of the Lynnhaven Inlet, as well where the James and Elizabeth rivers meet (Fig. 5c).

485 Given the importance of the Norfolk and Virginia Beach areas for commercial, recreational and 486 military maritime traffic, turtle-vessel interactions were to be expected. Sea turtles are

487 susceptible to interactions with vessel activity throughout their entire range, with vessel strikes

488 identified as an important mortality factor in several nearshore turtle habitats worldwide (Orós et 489 al. 2005, Chaloupka et al. 2008, Casale et al. 2010). In a Florida study, nearly all injuries

490 consistent with vessel strike on stranded sea turtles occurred antemortem or perimortem,

491 regardless of the level of carcass decomposition. These results suggest that vessel strikes seldom

492 occur with moderately to severely decomposed turtles which float above the water line (Brian

493 Stacy, personal communications). In Virginia, loggerheads appeared to be particularly affected

494 by vessels and rarely survived severe propeller trauma, especially if the trauma occurred in the

495 cranial two-thirds of the carapace (Barco et al. 2012a, Barco and Swingle 2014). Barco et al.

496 (2016) noted that the majority of loggerheads that stranded in the Bay with vessel damage

497 represented normal, healthy turtles prior to interactions, which suggests that mortality occurs as a 
direct result of lethal vessel-turtle contact. Our results complement this information by providing precise target areas for mitigation efforts to reduce probability of lethal vessel-turtle interactions. Overall, analysis of vessel strike mortality location predictions suggested that our model was a good predictor of mortality locations for stranded turtles. Our Monte Carlo randomization analysis indicates that mortality location predictions overlap vessel activity maps far more than one would expect at random (Fig. 8). Based on the overlap with vessel activity, the drift model was better at predicting mortality locations for stranded turtles classified as condition codes 1 and 2 than code 3 turtles. This is as one would expect, for turtles found in fresher decomposition conditions likely had only a short amount of time to drift before stranding, leading to lower uncertainty in their drift trajectory.

Although the analysis of turtles with evidence of death by watercraft interaction provided a good proxy for assessing model accuracy, the nature of the AIS boat position data underrepresents, and may misrepresent, overall vessel activity in the Bay. AIS provided a vast amount of real-time vessel track data, but was only legally required for non-federal vessels $65 \mathrm{ft}$ and larger, including large commercial vessels and industrial fishing vessels (Title 33, Code of Federal Regulations, Part 164). The data do not account for smaller commercial vessels and recreational vessels. Propeller lesions on stranded turtles in Virginia suggest that at least some portion of vessel strike mortality was due to smaller propellers that are common on smaller vessels (Barco et al. 2011). Furthermore, all vessels owned and operated by the U.S. government are legally exempt from AIS data reporting requirements (Title 33, Code of Federal Regulations, Part 164). The Chesapeake Bay has a significant number of military ports including the Norfolk Naval Base, which is the largest naval base in the world. In a study incorporating the use of AIS and RADAR data, researchers in southeastern Virginia found that military vessels had a 
521 distinctly different distribution than commercial vessels broadcasting AIS signals (Barco et al.

522 2012b). Therefore, identified regions of high vessel activity underestimate both the intensity and

523 spatial distribution of vessel activity in the study area. These differences between available data

524 and the real distribution of vessel traffic in the Bay likely explain the fact that model mortality

525 location predictions for a small number of vessel strike turtle strandings did not extensively

526 overlap vessel traffic data (e.g., if the strike was caused by a recreational vessel outside of

527 normal shipping channels; see pseudo-p-values $>0.5$ in Fig. 8).

\section{$528 \quad 4.2$ Potential fisheries interactions}

529 This study highlights novel methodology that significantly improved our ability to

530 identify possible locations of sea turtle mortality. However, a complete quantitative assessment

531 of overlaps between anthropogenic activities and these turtle mortality location predictions was

532 limited by the poor spatial and temporal resolution of fishing activity data, as well as the lack of

533 true measures of fishing effort, available for comparisons. This study represents a case where our

534 ability to model the biology (i.e., the drift and decomposition of turtle carcasses) exceeds our

535 ability to interpret model results in light of available anthropogenic observations. For instance,

536 data from VMRC at the waterway level were only accessible as an aggregation over the 6-year

537 study period, prohibiting comparisons on a month-year level. Thus, although there are noted

538 differences in mortality location for the spring peak compared to the remainder of the stranding

539 period, lack of temporal fisheries information makes it impossible to assess differences in

540 potential causes of mortality for the two different time periods. If data on anthropogenic

541 activities, such as fishing effort, were available on spatial and temporal scales pertinent for

542 interpreting individual stranding events (kilometers and a week to a month, respectively), then 
543 the overlap between these activities and mortality location predictions could be calculated and

544 one could quantitatively assess which activities were most likely to be causing the mortality.

545 For some human activities, such as large commercial vessel traffic, detailed information

546 were available and we were able to quantitatively compare and combine these data with

547 mortality predictions. For others, such as the purse-seine menhaden fishery, detailed data exist,

548 but were not publicly available due to industry confidentiality, public image and equity (among

549 fisheries) concerns. OMEGA Protein has operated the sole menhaden reduction plant along the

550 Atlantic coast since 2005 and controls all purse seine vessels (Kirkley 2011). Due to the single

551 participant in this fishery, purse seine fishery location data were not available from VMRC. We

552 requested data on purse seine fishing locations directly from OMEGA Protein, but our data

553 request was denied due to confidentiality concerns and fear of negative repercussions on the

554 image of the industry.

555 Ultimately, given these various data limitations, we could not definitively rule out any

556 fisheries as a cause of sea turtle mortality. However, preliminary qualitative comparisons can be

557 made between predicted mortality locations and the general distribution of Chesapeake Bay

558 fisheries. The distribution of sink/anchor gillnets, crab pots, and purse seine fishing overlap with

559 both distinct areas of high probability of sea turtle mortality: the lower James River region and

560 bayside Northampton County (Figs. 6, 7, 10-11). Mortality of both loggerhead and Kemp's

561 ridley turtles have been observed within Virginia's gillnet fisheries (Turtle Expert Working

562 Group 2000, Mansfield 2006). Sink gillnets in the nearshore waters of the Bay may interact with

563 bottom-feeding turtles as they forage for food. Crab pots pose a threat to turtles through

564 entanglement with vertical lines, but a side scan sonar survey conducted during the 2006 spring

565 peak of turtle strandings found no entanglements in any of the over 1,600 crab or whelk pots 
monitored (DeAlteris Associates Inc 2006). Menhaden purse seine effort overlaps with nearly all

567 probable mortality locations, with the notable exception of the region of high mortality

568 likelihood in the James River (Figs. 6-7, 11a). Although results from a 1992 study investigating

569 bycatch in the mid-Atlantic menhaden fishery found no sea turtles captured or even observed

570 during sampling, as well as particularly low bycatch within the Chesapeake Bay fleet, this study

571 observed catch as it was unloaded at the processing plant and did not observe fishing in action

572 (Austin et al. 1994). Measuring turtle interactions with these fisheries is an important avenue to

573 consider for future investigations.

574 The concentration of haul seine effort almost exclusively in the southwest quadrant of the

575 Bay aligns with predicted mortality locations near the James River and coastline of Hampton

576 County (Figs. 6-7, 10c), while high drift gillnet activity in the southeast region of the Bay

577 coincides with some of the probable mortality locations near Northampton County (Fig. 10a).

578 Minimal overlap is noted between probable mortality locations with whelk pots and traps and

579 staked gillnets (Figs. 6-7, 10d, 11b-c). Because of data pooling, we are unsure, however, if there

580 is temporal as well as spatial overlap between some of these fisheries and sea turtle strandings.

581 Although some likely mortality locations coincide with pound net usage in the northwest Bay, a

582 number of regulatory changes relating to use of modified pound net leaders were made to this

583 fishery in the mid-2000s specifically to reduce turtle mortality (67 FR 41196, 69 FR 24997, 71

584 FR 36024, 73 FR 68348). Research suggests that these regulations have resulted in a significant

585 reduction of pound net turtle entanglements (DeAlteris and Silva 2007, Silva et al. 2011).

586 Given the endangered status of sea turtles and potential societal and environmental

587 benefits of addressing threats in a timely fashion, data barriers surrounding the accessibility or

588 collect of fishing data should be lifted. Such information would allow for more complete 
assessments of potential drivers of sea turtle mortality in Virginia based on the predicted

590 mortality locations highlighted in this study. A combination of state fishery observer coverage,

591 vessel monitoring systems, and increasingly cheap tracking technologies will help address these

592 data deficiencies if funds are made available and fishery engagement can be achieved.

593 Additionally, although observer programs can provide direct evidence of sea turtle-fishery

594 interactions, the state of Virginia lacks an observer program capable of gathering these data for 595 most commercial state fisheries. The availability of data on anthropogenic activities on a finer

596 spatio-temporal scale is key to the ability to conduct more robust identifications of drivers that

597 threaten local sea turtle populations, as well as populations of other protected species.

\section{4.3 Future Research and Mitigation}

One study limitation lies in the model assumption that turtle carcasses are freely floating

600 at sea prior to beaching. Sea turtle carcasses in this area have been found entangled within

601 fishing gear, violating this assumption and thus limiting our ability to accurately predict the drift

602 trajectories of these individuals. Several fisheries (i.e. pound net, crab pot) are not checked daily

603 and gear soaks continuously, thus carcasses entangled within these gears can be discovered in a

604 fairly decomposed state and may represent individuals that have been omitted from analyses

605 based on their late condition code. It is also likely that some species and size classes of turtles are

606 more susceptible to types of fishing gears than others. In this study, stranding data of all species

607 and size classes were considered together, thus future research may consider investigating these

608 characteristics separately.

609 Sea turtle populations in the Chesapeake Bay have increased over time (Mansfield et al.

610 2004), thus the potential for interactions with fisheries may also increase as turtles become more

611 abundance in Virginia's waters. Limited information is available on the distribution of foraging 
612 sea turtles in the bay, but turtles are typically more abundant in the lower Bay (Mansfield 2006),

613 coinciding with many of the areas of high predicted sea turtle mortality locations. Research

614 suggests that loggerheads tend to stay primarily along channel edges and at river mouths, while

615 Kemp's ridleys are typically found in shallower waters, including seagrass beds (Keinath et al.

616 1987, Byles 1988). Additional research and information on the distribution of sea turtles in the

617 bay could be useful in further correlating the co-occurrence of sea turtles and human activities.

618 In addition, analyses in this study greatly relied on temperature-dependent carcass

619 decomposition at the sea surface. As bottom temperatures are lower than surface temperatures, it

620 is possible that cooler conditions will increase bottom time and cause carcasses to decompose

621 less quickly than modeled. This would result in a greater spread in the predicted area of mortality

622 and is an important avenue for future research. Finally, it is also worthwhile to note that the

623 coarse domain of the ChesROMS model may cause inaccurate simulation of pseudo-particles in

624 the coastal area. Using a model with higher horizontal resolution and/or an irregular grid that

625 better represents the complex coastline, such as the Semi-implicit Cross-scale Hydroscience

626 Integrated System Model (Ye et al. 2016, 2018), will be an important improvement to this

627 analysis in the future.

628 Overall, the ability to quantitatively assess overlap between the predicted sea turtle

629 mortality locations highlighted in this study with anthropogenic activities was severely limited

630 by the lack of fine-scale temporal and spatial resolutions of human use datasets. Nonetheless, the

631 spatio-temporal mortality information obtained from this study provided a starting point for

632 future research and mitigation. Slower vessel speeds are noted as the primary tool to reduce

633 vessel damage to sea turtles (Hazel et al. 2007), as well as marine mammals (Laist and Shaw

634 2006, Calleson and Frohlich 2007). However, using the results from this study, managers can 
635 consider strategies for boaters to reduce speeds in predicted areas with a high likelihood of

636 vessel-strike sea turtle mortality (Fig. 5b) and/or high probability of vessel-turtle interactions

637 during the times of year where turtles are abundant in these waters (Fig. 5c). A finer scale

638 analysis of vessel strikes based on propeller wound size could also be an area of future research.

639 Turtles that were completely bisected were likely to have interacted with larger vessels, and

640 those with multiple, parallel chop wounds were more likely to have interacted with smaller

641 vessels similar to many recreational vessels (Barco et al. 2011). Conducting separate large and

642 small vessel overlap analyses that include locations of marinas and boat ramps popular with

643 recreational vessels as a proxy for location may provide interesting insight into interaction by

644 vessel size.

645 Similarly, management regulations on commercial fisheries (i.e. time-area closures,

646 limited soak time) or gear modifications should be prioritized in time and space where there is an

647 increased likelihood of interaction with sea turtles. Energetic demands from spring migrations

648 cause turtles to be weaker and in poor health upon entering the Bay, and thus they may be at a

649 greater risk of negative interaction with fishing gear if caught in strong currents (Bellmund et al.

650 1987, Byles 1988). In addition, it is possible that turtles stranding during the spring peak are

651 weakened from predisposed conditions or cryptic mortality occurring during their migration into

652 the Bay. The cooler water temperature at this time of the year may also slow the metabolism of

653 the migrating turtles, further weakening them. However, by the time mortalities drop near the

654 end of June, water temperatures have increased and turtles are able to forage and move around

655 nets with minimal threat (Lutcavage and Musick 1985, Byles 1988). Therefore, from a temporal

656 standpoint, management efforts may choose to prioritize implementing regulations during this

657 vulnerable spring peak time period. 
Predicted mortality locations for turtles classified as having no apparent injuries or where

659 cause of stranding was unable to be assessed were noted to differ within the spring peak

660 compared to the rest of the stranding season, generally shifting from the southwest portion of the

661 Bay to southeastern waters near the bayside of Northampton County (Figs. 6-7). Some maps also

662 show a shift in mortality locations from the lower Bay to more northern Virginia areas of the

663 Bay, consistent with movement of turtles higher into the Bay as the foraging season progresses.

664 Thus, rolling regulations taking into account turtle behavior and distribution during different

665 times of the stranding season could be effective.

666 Compared to the rest of the stranding season, the elevated number of documented

667 strandings during the spring peak has generally been interpreted as indicative of higher sea turtle

668 mortality rates during this time period. Nevertheless, it is possible that sea turtle mortality is

669 constant throughout the spring and summer stranding season, but turtles are more likely to

670 succumb to decomposition and sink before making landfall during summer, leading to fewer

671 stranding observations. Turtles decompose at a slower rate in cooler waters (Higgins et al. 1995,

672 Santos et al. 2018), with results from Santos et al. (2018) suggesting that turtle carcasses have

673 the potential to drift $\sim 2-5$ days longer and $\sim 15-30 \mathrm{~km}$ further during the cooler spring peak

674 period compared to those turtles that die during the hot summer months (Fig. 4). This difference

675 in drift duration could explain variability in stranding rates during the spring/summer foraging

676 season, though this hypothesis is difficult to quantitatively assess without knowing more about

677 the spatial distribution of true turtle mortality in the Bay. This hypothesis is also consistent with

678 a small fall peak in strandings (Coles 1999, Barco and Swingle 2014), during which time we

679 predict that drift durations should be significantly longer than during the summer. Therefore, 
680 although management actions may prioritize mitigation measures during the spring peak period,

681 strong protection of turtle populations is crucial throughout their entire residency in the Bay.

682 4.4 Conclusions

683 The results of this study provide the first attempt to predict sea turtle mortality location

684 based on condition code for Virginia waters of the Chesapeake Bay. Despite data limitations,

685 these results provide ample material for developing focused time-area management measures for

686 mitigating sea turtle mortality in the Bay. Although it is difficult to acquire reliable data on lethal

687 fisheries interactions without trained observers in state fisheries, even rough estimates of causes

688 of mortality and distribution of turtle mortality can provide significant information to inform the

689 development of effective management strategies. Given the protected status of sea turtles and

690 importance of the Chesapeake Bay for hundreds of turtles each year, targeted mitigation

691 measures are urgently needed to ensure the persistence of local turtle populations. Furthermore,

692 as temperatures increase due to climate change, the Bay is predicted to become more favorable to

693 sea turtles (Pike 2014), and, therefore, it is important to identify and manage for anthropogenic

694 causes of mortality now before there has been a significant increase in turtle usage of the Bay.

695 Future research and regulatory management efforts should focus on obtaining more detailed

696 spatio-temporal data on anthropogenic activities so that the list of potential mortality drivers can

697 be mitigated based on quantitative comparisons between the distributions of these activities and

698 mortality location predictions, as well as on assessing probability of landfall for different areas of

699 the Bay so as to estimate absolute turtle mortality rates. The experimental and modeling methods

700 developed here provide a sound basis for these future efforts, as well as a template for assessing

701 and understanding stranding data for sea turtles and other marine megafauna around the globe. 


4

We would like to thank all the staff, volunteers and interns at the Virginia Aquarium \& Marine Science Center Stranding Response Program for collection of the stranding data used in this study. Funding for this project was provided through the College of William and Mary's Green Fee Funding, the Virginia Institute of Marine Science (VIMS), the VIMS GK-12 Sheldon H. Short Trust Program, the Dominion Foundation and Virginia Sea Grant. This work was performed in part using computational facilities at the College of William and Mary which were provided with the assistance of the National Science Foundation, the Virginia Port Authority, Sun Microsystems, and Virginia's Commonwealth Technology Research Fund. The paper is Contribution No. 3753 of the Virginia Institute of Marine Science, College of William \& Mary.

(1)


Austin, H., J. Kirkley, and J. Lucy. 1994. By-catch and the Fishery for Atlantic Menhaden, Brevoortia Tyrannus in the Mid-Atlantic Bight: An Assessment of the Nature and Extent of By-catch. Virginia Sea Grant Marine Advisory No. 53. Gloucester Point, VA.

Barco, S. G., L. R. D’Eri, C. M. Trapani, S. J. Davis, and W. M. Swingle. 2012a. Using stranded

Barco, S. G., G. G. Lockhart, S. A. Rose, S. Mallette, W. M. Swingle, and R. Boettcher. 2015. loggerhead sea turtles to compare lethal and non-lethal vessel trauma. Presented at the Annual Symposium on Sea Turtle Biology and Conservation. Huatulco, Oaxaca, Mexico, Virginia/Maryland sea turtle research \& conservation initiative. Final Report to NOAA for Award \#NA09NMF4720033. VAQF Scientific Report 2015-05. 37pp.

Barco, S. G., G. G. Lockhart, and W. M. Swingle. 2012b. Using AIS \& RADAR to investigate ship behavior in the Chesapeake Bay ocean approach off of Virginia, USA. Presented at IEEE OCEANS '12, Oct 2012, Virginia Beach, VA.

Barco, S. G., C. M. Trapani, and A. M. Costidis. 2011. Inferring vessel characteristics from wounds on stranded sea turtles: Can we apply the manatee method? In: Proceedings of the Thirty-first Annual Symposium on Sea Turtle Biology and Conservation. NOAA Technical Memorandum NOAA NMFS-SEFSC-631322p.

Barco, S., M. Law, B. Drummond, H. Koopman, C. Trapani, S. Reinheimer, S. Rose, W. M. Swingle, and A. Williard. 2016. Loggerhead turtles killed by vessel and fishery interaction in Virginia, USA, are healthy prior to death. Marine Ecology Progress Series 555:221-234.

Barco, S., and W. M. Swingle. 2014. Sea Turtle Species in the Coastal Waters of Virginia: Analysis of stranding and survey data. VAQF Scientific Report \#2014-07b, Virginia 

Aquarium \& Marine Science Center Foundation. Virginia Beach, VA.

754 Bellmund, S., J. A. Musick, R. Klinger, R. Byles, J. A. Keinath, and D. Barnard. 1987. Ecology 755 of sea turtles in Virginia. Scientific Report No. 119, Virginia Institute of Marine Science. $756 \quad$ Gloucester Point, VA.

757 Byles, R. A. 1988. Behavior and Ecology of Sea Turtles from Chesapeake Bay, Virginia. PhD 758 Dissertation, School of Marine Science, The College of William and Mary, Gloucester 759 Point, VA.

760 Calleson, C. S., and R. K. Frohlich. 2007. Slower boat speeds reduce risks to manatees.

$761 \quad$ Endangered Species Research 3:295-304.

762 Carniel, S., G. Umgiesser, M. Sclavo, L. H. Kantha, and S. Monti. 2002. Tracking the drift of a 763 human body in the coastal ocean using numerical prediction models of the oceanic, $764 \quad$ atmospheric and wave conditions. Science \& justice 42:143-151.

765 Casale, P., M. Affronte, G. Insacco, D. Freggi, C. Vallini, P. D’Astore, P. Astore, R. Basso, G. 766 Paolillo, G. Abbate, and R. Argano. 2010. Sea turtle strandings reveal high anthropogenic 767 mortality in Italian waters. Aquatic Conservation: Marine and Freshwater Ecosystems $768 \quad 20: 611-620$.

769 Ceriani, S. A., J. F. Weishampel, L. M. Ehrhart, K. L. Mansfield, and M. B. Wunder. 2017.

770 Foraging and recruitment hotspot dynamics for the largest Atlantic loggerhead turtle $771 \quad$ rookery. Scientific Reports 7.

772 Chaloupka, M., T. M. Work, G. H. Balazs, S. K. K. Murakawa, and R. Morris. 2008. Cause773 specific temporal and spatial trends in green sea turtle strandings in the Hawaiian 774 Archipelago (1982-2003). Marine Biology 154:887-898.

775 Coles, W. C. 1999. Aspects of the Biology of Sea Turtles in the Mid-Atlantic Bight. PhD 
Dissertation, The School of Marine Science, College of William \& Mary. Gloucester Point, VA.

Conant, T. A., P. H. Dutton, T. Eguchi, S. P. Epperly, C. C. Fahy, M. H. Godfrey, S. L. MacPherson, E. E. Possardt, B. A. Schroeder, J. A. Seminoff, M. L. Snover, C. M. Upite, and B. E. Witherington. 2009. Loggerhead sea turtle (Caretta caretta) 2009 status review

Crain, C. M., B. S. Halpern, M. W. Beck, and C. V Kappel. 2009. Understanding and Managing

Da, F. 2018. Impacts of Direct Atmospheric Nitrogen Deposition and Coastal Nitrogen Fluxes on Biology, 2009. Annals of the New York Academy of Sciences 1162:39-62.

Chesapeake Hypoxia. MS Thesis, Virginia Institute of Marine Science, College of William \& Mary.

\section{DeAlteris, J., and R. Silva. 2007. Performance in 2004 and 2005 of an alternative leader design} on the bycatch of sea turtles and the catch of finfish in Chesapeake Bay pound nets,

offshore Kiptopeake, VA. National Marine Fisheries Service, New England Fisheries offshore Kiptopeake, VA. National
Science Center. Woods Hole, MA.

DeAlteris Associates Inc. 2006. Sea turtle-pot fishery interaction survey: Chesapeake Bay and coastal waters of Virginia. Final report submitted to the National Marine Fisheries Service. Woods Hole, MA.

Epperly, S. P., J. Braun, A. J. Chester, F. A. Cross, J. V Merriner, P. A. Tester, and J. H. Churchill. 1996. Beach strandings as an indicator of at-sea mortality of sea turtles. Bulletin of Marine Science 59:289-297. 
Feng, Y., M. A. M. Friedrichs, J. Wilkin, H. Tian, Q. Yang, E. E. Hofmann, J. D. Wiggert, and R. R. Hood. 2015. Chesapeake Bay nitrogen fluxes derived from a land-estuarine ocean biogeochemical modeling system: Model description, evaluation, and nitrogen budgets. Journal of Geophysical Research: Biogeosciences 120:1666-1695.

Finkbeiner, E. M., B. P. Wallace, J. E. Moore, R. L. Lewison, L. B. Crowder, and A. J. Read. 2011. Cumulative estimates of sea turtle bycatch and mortality in USA fisheries between 1990 and 2007. Biological Conservation 144:2719-2727.

Garavelli, L., A. Grüss, B. Grote, N. Chang, M. Smith, P. Verley, E. K. Stenevik, D. M. Kaplan, and C. Lett. 2012. Modeling the dispersal of Cape hake ichthyoplankton. Journal of plankton research 34:655-669.

George, R. H. 1997. Health problems and diseases of sea turtles. Pages 363-386in P. L. Lutz and J. A. Musick, editors.The biology of sea turtles, volume I. CRC Press, Boca Raton, FL.

Gulland, F. M. D., and A. J. Hall. 2007. Is marine mammal health deteriorating? Trends in the global reporting of marine mammal disease. EcoHealth 4:135-150.

Hart, K. M., P. Mooreside, and L. B. Crowder. 2006. Interpreting the spatio-temporal patterns of sea turtle strandings: going with the flow. Biological Conservation 129:283-290.

Hazel, J., I. R. Lawler, H. Marsh, and S. Robson. 2007. Vessel speed increases collision risk for the green turtle Chelonia mydas. Endangered Species Research 3:105-113.

Heithaus, M. R., A. J. Wirsing, J. A. Thomson, and D. A. Burkholder. 2008. A review of lethal and non-lethal effects of predators on adult marine turtles. Journal of Experimental Marine Biology and Ecology 356:43-51.

Higgins, B., A. Cannon, and G. Gitschlag. 1995. Sea turtle decomposition study. Unpublished report, National Marine Fisheries Service, Southeast Fisheries Science Center. Galveston, 
TX.

823 Irby, I. D., M. A. Friedrichs, F. Da, and K. E. Hinson. 2017. The Competing Impacts of Climate 824 Change and Nutrient Reductions on Dissolved Oxygen in the Chesapeake Bay.

825 Biogeosciences Discussions.

826 Irby, I. D., M. A. M. Friedrichs, C. T. Friedrichs, A. J. Bever, R. R. Hood, L. W. J. Lanerolle, M.

827 Li, L. Linker, M. E. Scully, K. Sellner, J. Shen, J. Testa, H. Wang, P. Wang, and M. Xia.

828 2016. Challenges associated with modeling low-oxygen waters in Chesapeake Bay: A

829 multiple model comparison. Biogeosciences 13:2011-2028.

830 Keinath, J. A., R. Byles, and J. A. Musick. 1987. Aspects of the biology of Virginia's sea turtles:

831 1979-1986. Virginia Journal of Science 38:329-336.

832 Kirkley, J. E. 2011. An Assessment of the Social and Economic Importance Of Menhaden

833 (Brevoortia tyrannus) (Latrobe, 1802) in Chesapeake Bay Region. VIMS Marine Resource

834 Report No. 2011-14. Gloucester Point, VA.

835 Koch, V., H. Peckham, A. Mancini, and T. Eguchi. 2013. Estimating at-sea mortality of marine

836 turtles from stranding frequencies and drifter experiments. PloS one 8:e56776.

837 Laist, D. W., and C. Shaw. 2006. Preliminary evidence that boat speed restrictions reduce deaths 838 of Florida manatees. Marine Mammal Science 22:472-479.

839 Learmonth, J. A., C. D. Macleod, M. B. Santos, G. J. Pierce, H. Q. P. Crick, and R. A. Robinson. 840 2006. Potential Effects of Climate Change on Marine Mammals. Oceanography and Marine $841 \quad$ Biology 44:431-464.

842 Lett, C., P. Verley, C. Mullon, C. Parada, T. Brochier, P. Penven, and B. Blanke. 2008. A

843 Lagrangian tool for modelling ichthyoplankton dynamics. Environmental Modelling \&

$844 \quad$ Software 23:1210-1214. 
845

846

847

848

849

850

851

852

853

854

855

856

857

858

859

860

861

862

863

864

865

866

867

Lewison, R. L., L. B. Crowder, A. J. Read, and S. A. Freeman. 2004. Understanding impacts of fisheries bycatch on marine megafauna. Trends in Ecology and Evolution 19:598-604.

Lewison, R. L., L. B. Crowder, B. P. Wallace, J. E. Moore, T. Cox, R. Zydelis, S. McDonald, A. DiMatteo, D. C. Dunn, C. Y. Kot, R. Bjorkland, S. Kelez, C. Soykan, K. R. Stewart, M. Sims, A. Boustany, A. J. Read, P. Halpin, W. J. Nichols, and C. Safina. 2014. Global patterns of marine mammal, seabird, and sea turtle bycatch reveal taxa-specific and cumulative megafauna hotspots. Proceedings of the National Academy of Sciences of the United States of America 111:5271-6.

Luettich, R. A., L. D. Wright, C. R. Nichols, R. Baltes, M. A. . Friedrichs, A. Kurapov, A. J. van der Westhuysen, K. Fennel, and E. Howlett. 2017. A U.S Integrated Ocean Observing System Coastal and Ocean Modeling Testbed to improve understanding and operational forecasts of extreme events and chronic environmental conditions. Eos 98.

Lutcavage, M., and J. A. Musick. 1985. Aspects of the biology of sea turtles in Virginia. Copeia 1985:449-456.

Mansfield, K. L. 2006. Sources of mortality, movements and behavior of sea turtles in Virginia. PhD Dissertation, Virginia Institute of Marine Science, College of William \& Mary, Gloucester Point, VA.

Mansfield, K. L., J. A. Musick, and K. L. Frisch. 2004. 2003 Aerial Sea Turtle Survey IN THE Chesapeake Bay, Virginia.

Mansfield, K. L., J. A. Musick, and R. A. Pemberton. 2001. Characterization of the Chesapeake Bay Pound Net and Whelk Pot Fisheries and Their Potential Interactions with Marine Sea Turtle Species. Final report, Northeast National Marine Fisheries Service. Contract \#43EANFO30131. Woods Hole, MA. 
Mansfield, K. L., V. S. Saba, J. A. Keinath, and J. A. Musick. 2009. Satellite tracking reveals a dichotomy in migration strategies among juvenile loggerhead turtles in the Northwest Atlantic. Marine Biology 156:2555-2570.

Mesinger, F., G. DiMego, E. Kalnay, K. Mitchell, P. C. Shafran, W. Ebisuzaki, D. Jović, J. Woollen, E. Rogers, E. H. Berbery, M. B. Ek, Y. Fan, R. Grumbine, W. Higgins, H. Li, Y. Lin, G. Manikin, D. Parrish, W. Shi, F. Mesinger, G. DiMego, E. Kalnay, K. Mitchell, P. C. Shafran, W. Ebisuzaki, D. Jović, J. Woollen, E. Rogers, E. H. Berbery, M. B. Ek, Y. Fan, R. Grumbine, W. Higgins, H. Li, Y. Lin, G. Manikin, D. Parrish, and W. Shi. 2006. North American Regional Reanalysis. Bulletin of the American Meteorological Society 87:343360.

Moore, M. J., J. Van Der Hoop, S. G. Barco, A. M. Costidis, F. M. Gulland, P. D. Jepson, K. T. Moore, S. Raverty, and W. A. McLellan. 2013. Criteria and case definitions for serious injury and death of pinnipeds and cetaceans caused by anthropogenic trauma. Diseases of Aquatic Organisms 103:229-264.

Moriarty, J. M. 2017. The Role of Seabed Resuspension on Oxygen and Nutrient Dynamics in Coastal Systems: A Numerical Modeling Study. PhD Dissertation, Virginia Institute of Marine Science, College of William \& Mary.

Musick, J. A., and C. J. Limpus. 1997. Habitat utilization and migration in juvenile sea turtles. Pages 137-163 in P. L. Lutz and J. A. Musick, editors. The biology of sea turtles. CRC Press, Boca Rouge, FL.

Nero, R. W., M. Cook, A. T. Coleman, M. Solangi, and R. Hardy. 2013. Using an ocean model to predict likely drift tracks of sea turtle carcasses in the north central Gulf of Mexico. Endangered Species Research 21:191-203. 
NMFS. 2011. Endangered and Threatened Species: Determination of Nine Distinct Population Segments of Loggerhead Sea Turtles as Endangered or Threatened; Final Rule to List 9 Distinct Population Segments (DPSs) of Loggerhead Sea Turtles Under the ESA.

Orós, J., A. Torrent, P. Calabuig, and S. Déniz. 2005. Diseases and causes of mortality among sea turtles stranded in the Canary Islands, Spain (1998-2001). Diseases of Aquatic Organisms 63:13-24.

Peltier, H., W. Dabin, P. Daniel, O. Van Canneyt, G. Dorémus, M. Huon, and V. Ridoux. 2012. The significance of stranding data as indicators of cetacean populations at sea: Modelling the drift of cetacean carcasses. Ecological Indicators 18:278-290.

Pike, D. A. 2014. Forecasting the viability of sea turtle eggs in a warming world. Global Change Biology 20:7-15.

Santos, B. S., D. M. Kaplan, M. A. M. Friedrichs, S. G. Barco, K. L. Mansfield, and J. P. Manning. 2018. Consequences of drift and carcass decomposition for estimating sea turtle mortality hotspots. Ecological Indicators 84:319-336.

SEDAR. 2015. SEDAR 40 - Atlantic Menhaden Stock Assessment Report. North Carolina, SC.

Silva, L. A. 1996. State Fishery Interactions wtih Protected Species from Maine to Maryland, Special Report No. 54 of the Atlantic States Marine Fisheries Comission. Pages 64-72 in T. Berger, editor. Proceedings of the Workshop on the Management of Protected Species/Fisheries Interactions in State Waters.

Silva, R. D., J. T. DeAlteris, and H. O. Milliken. 2011. Evaluation of a pound net leader designed to reduce sea turtle bycatch. Marine Fisheries Review 73:36-45.

Swingle, W. M., M. C. Lynott, E. B. Bates, L. R. D’Eri, G. G. Lockhart, K. M. Phillips, and M. D. Thomas. 2016. Virginia Sea Turtle and Marine Mammal Stranding Network 2015 Grant 
915 Grant \#NA14NOS4190141, Task 49. VAQF Scientific Report 2016-01. Virginia Beach, $916 \quad$ VA.

917 Turtle Expert Working Group. 2000. Assessment Update for the Kemp's Ridley and Loggerhead 918 Sea Turtle Populations in the Western North Atlantic. Page U.S. Department of Commerce 919 NOAA Technical Memorandum NMFS-SEFSC-444.

920 Virginia Tourism Corporation. 2015. Coastal Virginia Regional Travel Profile. VA Module of 921 TNS TravelsAmerica, FY2015. Retrived from:

922 https://www.vatc.org/uploadedFiles/Research/CoastalVirginiaTripProfileFY2015VAModul 923 e.pdf.

924 Wallace, B. P., C. Y. Kot, A. D. Dimatteo, T. Lee, L. B. Crowder, and R. L. Lewison. 2013. 925 Impacts of fisheries bycatch on marine turtle populations worldwide: Toward conservation 926 and research priorities. Ecosphere 4:40.

927 Wallace, B. P., R. L. Lewison, S. L. Mcdonald, R. K. Mcdonald, C. Y. Kot, S. Kelez, R. K. 928 Bjorkland, E. M. Finkbeiner, S. Helmbrecht, and L. B. Crowder. 2010. Global patterns of 929 marine turtle bycatch. Conservation Letters 3:131-142.

930 Ye, F., Y. J. Zhang, M. A. M. Friedrichs, H. V. Wang, I. D. Irby, J. Shen, and Z. Wang. 2016. A 931 3D, cross-scale, baroclinic model with implicit vertical transport for the Upper Chesapeake 932 Bay and its tributaries. Ocean Modelling.

933 Ye, F., Y. J. Zhang, H. V. Wang, M. A. M. Friedrichs, I. D. Irby, E. Alteljevich, A. Valle-

934 Levinson, Z. Wang, H. Huang, J. Shen, and J. Du. 2018. A 3D unstructured-grid model for 935 Chesapeake Bay: importance of bathymetry. Ocean Modelling.

936 Zollett, E. A. 2009. Bycatch of protected species and other species of concern in US east coast 

commercial fisheries. Endangered Species Research 9:49-59.

938 Tables

939 Table 1. Linear regression parameters including the y-intercept (Y-int.), slope, and significance

940 (signif.), from the decomposition study, relating temperature with minimum (min) and maximum

941 (max) buoyancy times during condition codes 1-3. Note that the y-intercept has been adjusted by

9421 to account for the assumption that code 1 turtles are buoyant for only one day. Condition code

9431 and minimum time of buoyancy for condition code 2 is not based on experimental data, thus

944 significance values are not reported.

945

\begin{tabular}{|ccccc|}
\hline Time period & Condition code & Y-int. & Slope & Signif. \\
\hline Min & 1 & 0 & 0 & N/A \\
Max & 1 & 1 & 0 & N/A \\
Min & 2 & 1 & 0 & N/A \\
Max & 2 & 14.99206 & -0.41947 & $<0.01$ \\
Min & 3 & 16.7177 & -0.5021 & $<0.05$ \\
Max & 3 & 29.3221 & -0.9079 & $<0.01$ \\
\hline
\end{tabular}

946 
947

948

949

950

951

952

953

954

955

956

957

958

959

960

961

962

963

964

965

966

967

968

969

\section{Figure Legends}

Figure 1. (A) Domain of the ChesROMS model. (B) Location of top three areas with reported sea turtle strandings in Virginia from 2009-2014, including 1) the bayside of Northampton County, 2) Norfolk, and 3) Virginia Beach. (C) Expanded view of the lower Chesapeake Bay.

Figure 2. Criteria that must be met for each pseudo-particle to be considered "successful" for a particular stranding event.

Figure 3. Duration of positive buoyancy (days) vs average water temperature $\left({ }^{\circ} \mathrm{C}\right)$ based on results from the experimental decomposition study (Santos et al. 2018). Shaded region represents the time period of positive buoyancy for turtles classified as condition code 1 (green), code 2 (yellow) and code 3 (red). As turtles in condition code 1 were not observed in the study, code 1 turtles were assigned a maximum drift duration of 1 day, and drift duration for turtles with condition codes 2 and 3 were increased by 24 hours relative to raw results from the decomposition study. Individual data points are represented for code 2 turtles and code 3 turtles, with shapes representing the minimum (circle) and maximum (triangle) duration a floating carcass spent in each condition code. Solid lines represent linear regressions.

Figure 4. Boxplot of average (A) drift times (days) and (B) drift distances (km) of modeled particles leading to a condition code 3 stranding event. Results are aggregated by week of the year with gray-colored boxes representing strandings occurring during the spring peak time period. (C) Linear regression of drift time (days) vs drift distance $(\mathrm{km})$.

Figure 5. (A) Vessel density (\%) based on vessel location data from the Automatic Identification System for non-federal vessels $\geq 65 \mathrm{ft}$ traveling faster than $4 \mathrm{~km} / \mathrm{hr}$. (B) Relative particle 
density (\%) for probability of point of origin for turtle mortality leading to a stranding and classified with probable cause of death as vessel strike. (C) Combined joint probability (\%) depicting the overlap between vessel activity and the predicted mortality locations of vessel strike strandings.

974 Figure 6. Relative particle density (\%) for probability of point of origin for turtle mortality

Figure 7. Relative particle density (\%) for probability of point of origin for turtle mortality Commission waterways. Note that the scales for codes 2 and 3 s have been standardized across time periods. right, panels give results for code 1 , code 2 and code 3 strandings, respectively. White circles represent stranding locations and black lines represent Virginia Marine Resource leading to a stranding and classified with probable cause of death as unable to assess during (A) the spring peak and (B) the remainder of the stranding period. From left to right, panels give results for code 1 , code 2 and code 3 strandings, respectively. Code 1 strandings were only reported during the spring peak period. White circles represent stranding locations and black lines represent Virginia Marine Resource Commission waterways. Note that the scales for codes 2 and 3 s have been standardized across time periods.

Figure 8. Results from Monte Carlo analysis depicting the probability density function that the model predicted overlap is better $(\mathrm{p}<0.05)$ at predicting overlap with vessel activity than Monte Carlo randomly distribution null models. Colored lines represent p-values for 
992

993

994

995

996

997

998

999

1000

1001

1002

1003

1004

1005

1006

1007

condition code 1 (blue), 2 (green), and 3 (red). The black solid line represents a significance value of 0.05 .

Figure 9. Relative particle density (\%) for probability of point of origin for turtle mortality leading to a stranding classified as condition code 2 with no apparent injuries during the spring peak. Results include (A) $0 \%$, (B) $2 \%$, and (C) $4 \%$ of direct wind forcing on carcass drift, as well as (D) the mean of the results with the varying wind forcing values combined. Note that the color scales have been standardized.

Figure 10. Harvest (hundreds of thousands of pounds) by (A) drift gillnets, (B) sink/anchor gillnets, (C) haul seines, (D) whelk pots and traps and (E) crab pots and traps gear. Data was obtained from the Virginia Marine Resource Commission and aggregated over 20092014.

Figure 11. (A) Menhaden purse seine sets locations (red) aggregated over 2011-2013, obtained from the 2015 Atlantic Menhaden Stock Assessment Report. Length (km) of net per $5 \mathrm{~km}$ by $5 \mathrm{~km}$ grid cell for (B) staked gill nets and (C) pound nets based on point locations obtained from the Virginia Marine Resource Commission website for 2017, the current license year at the time of the study. 
1008 Figures

1009 Figure 1
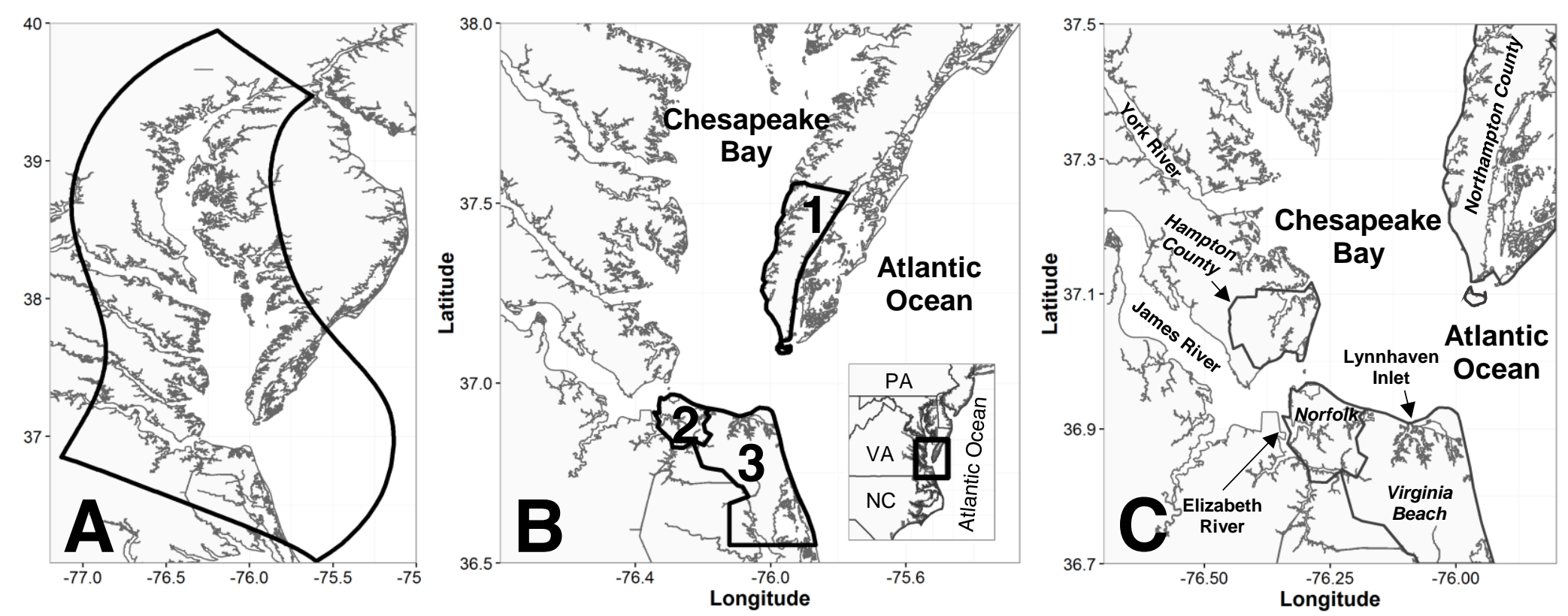
1010 Figure 2

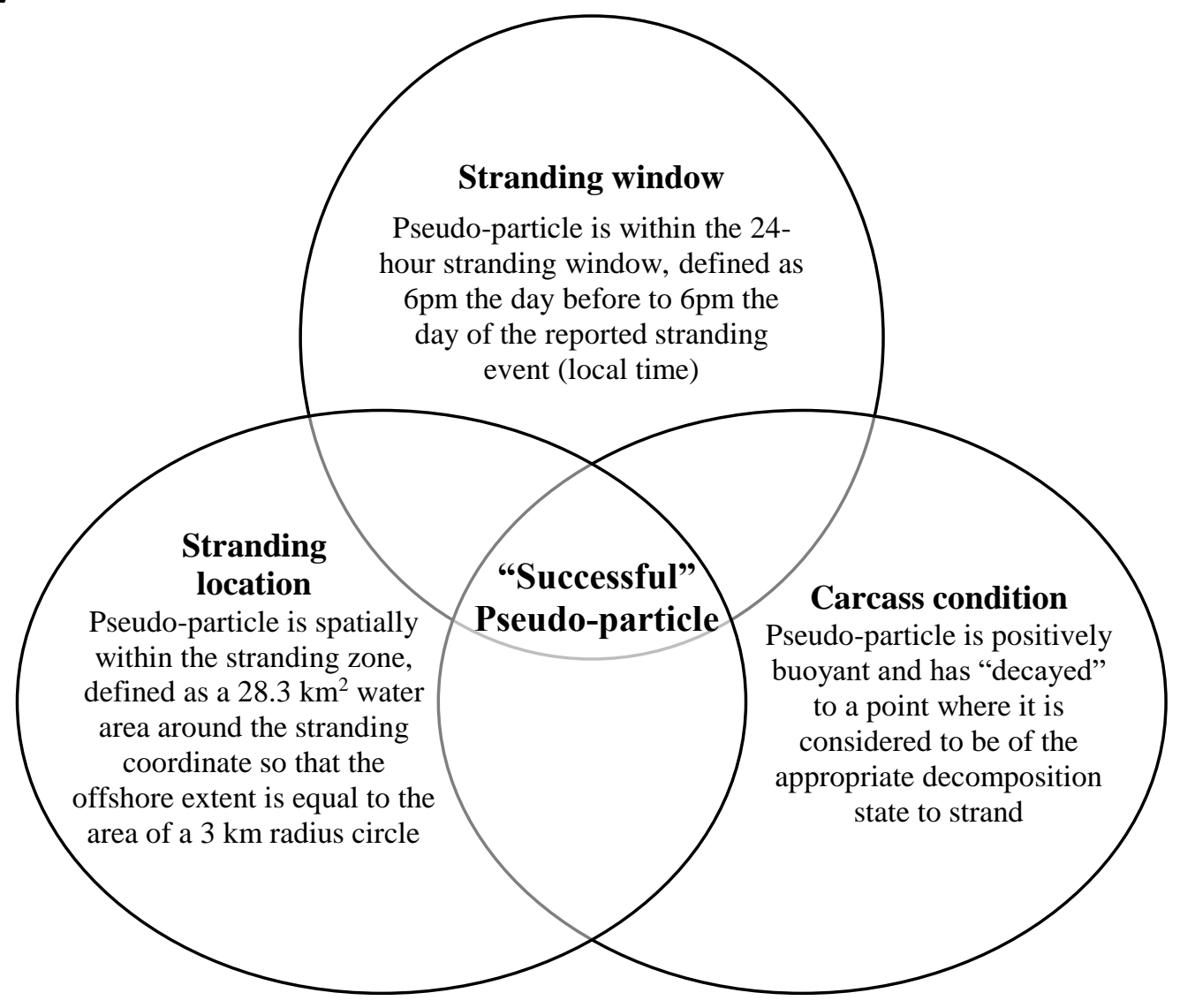


1011 Figure 3

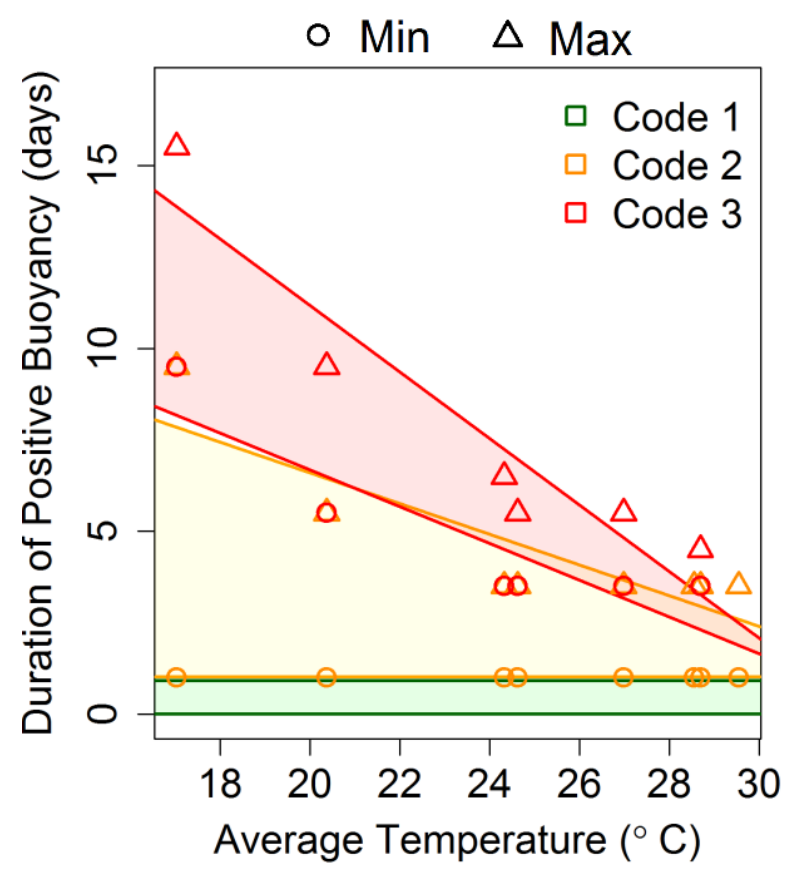


1012 Figure 4
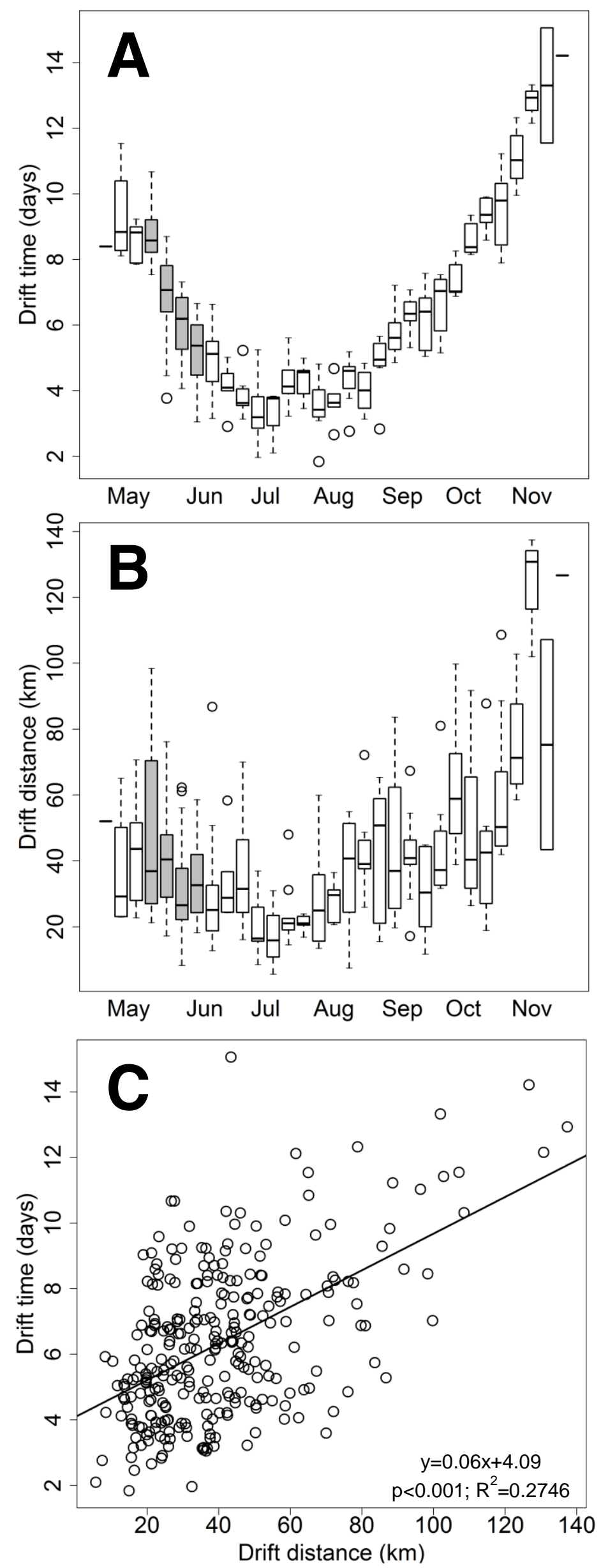


\section{Figure 5}
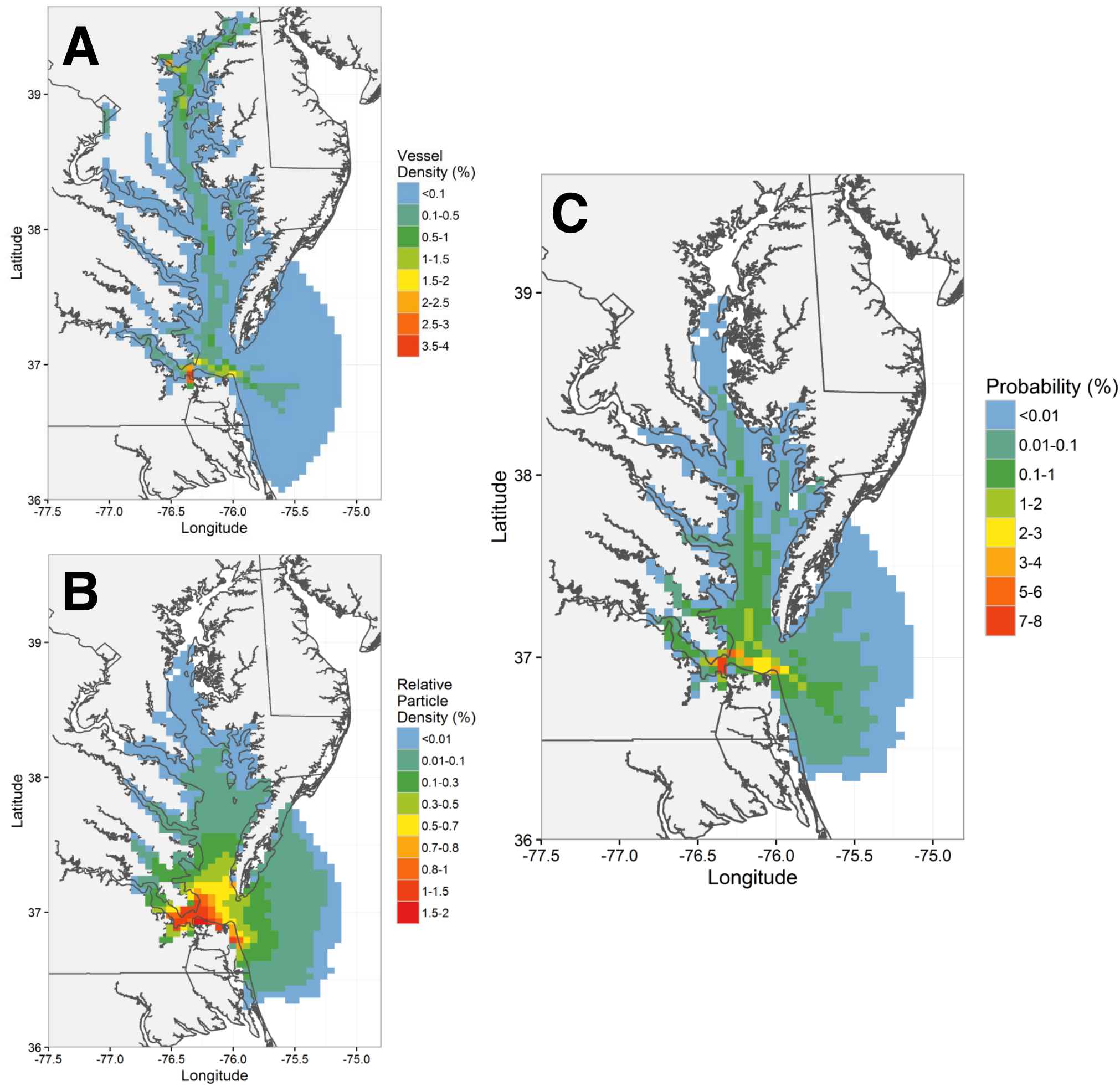


\section{(A) Spring Peak}
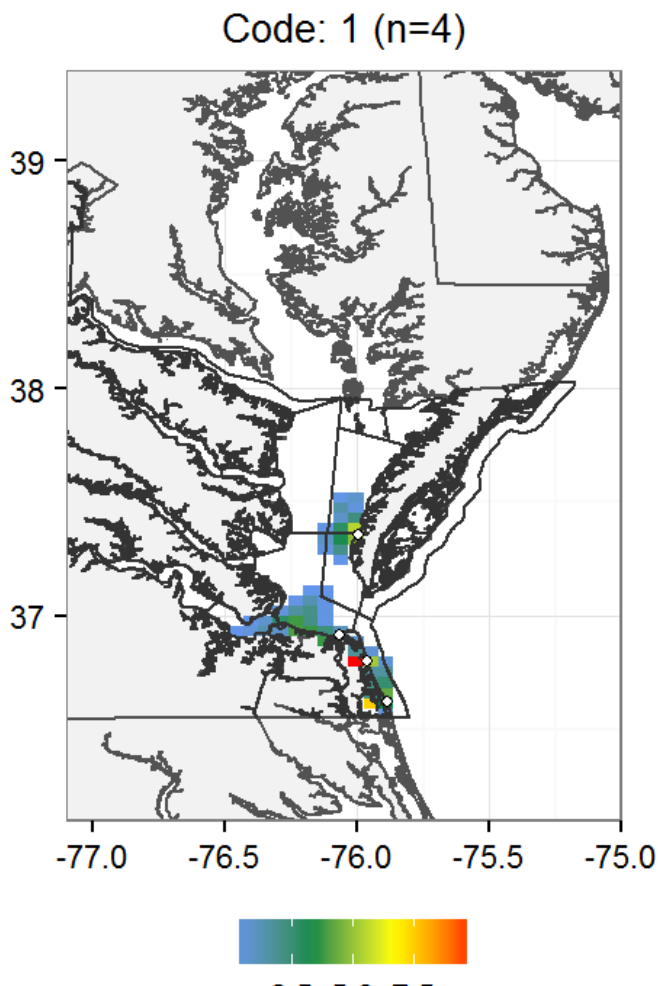

2.55 .07 .5
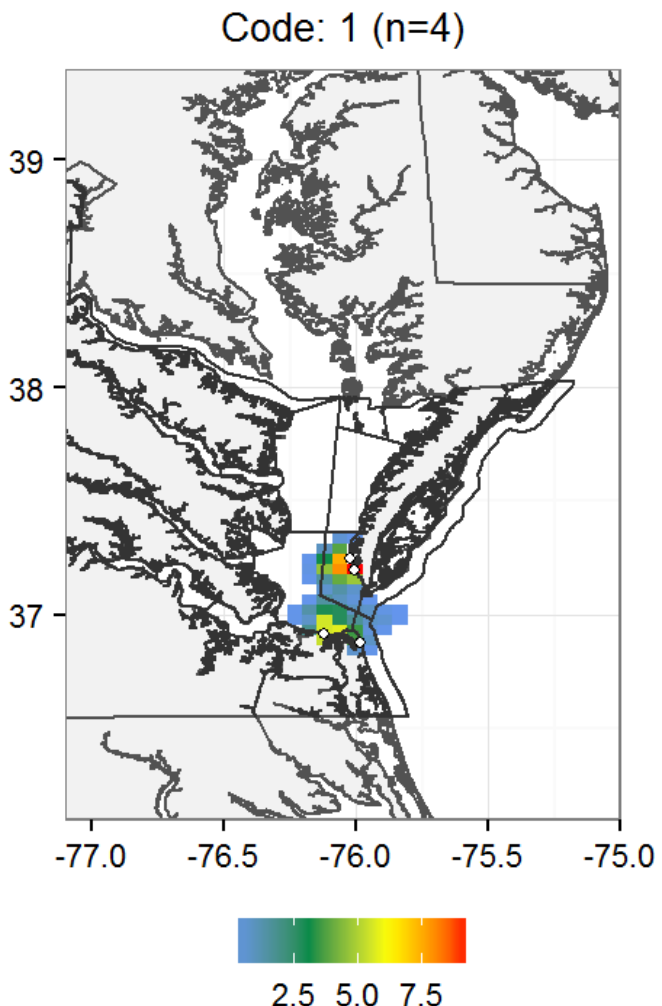
Code: $2(n=45)$
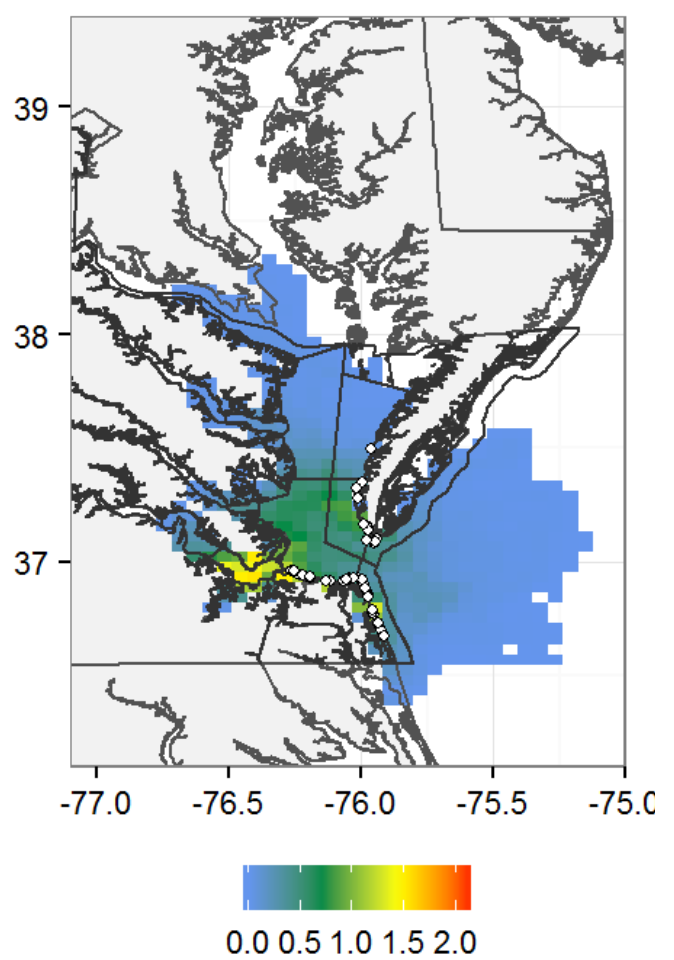

(B) Remaining stranding period Code: $2(\mathrm{n}=63)$
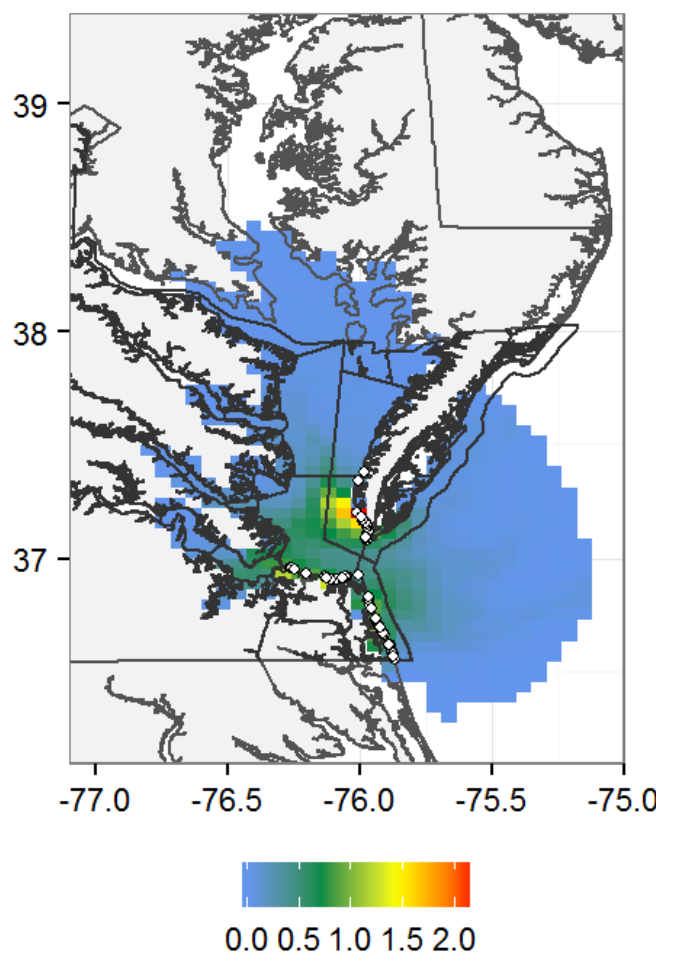

Code: $3(n=18)$

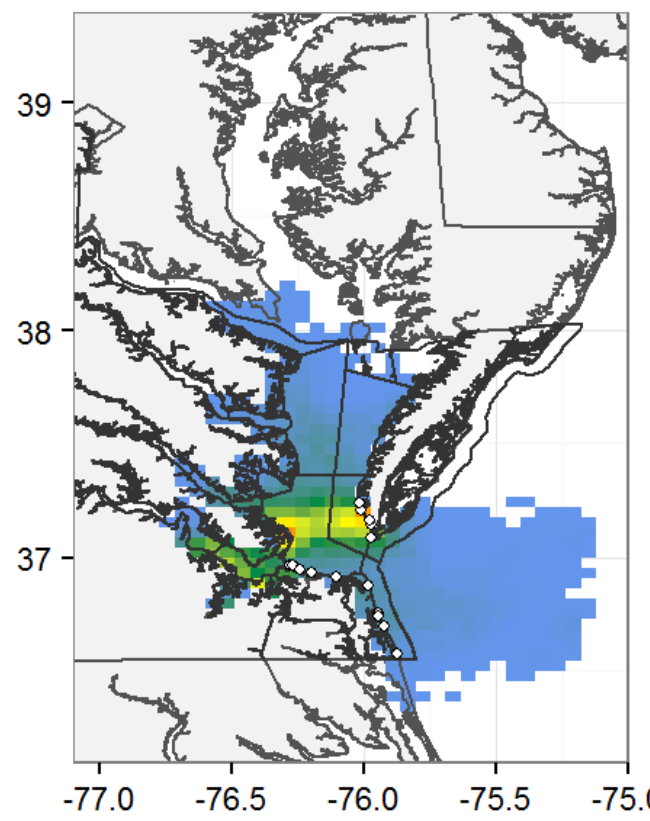

0.00 .51 .01 .52 .0

Code: $3(n=25)$

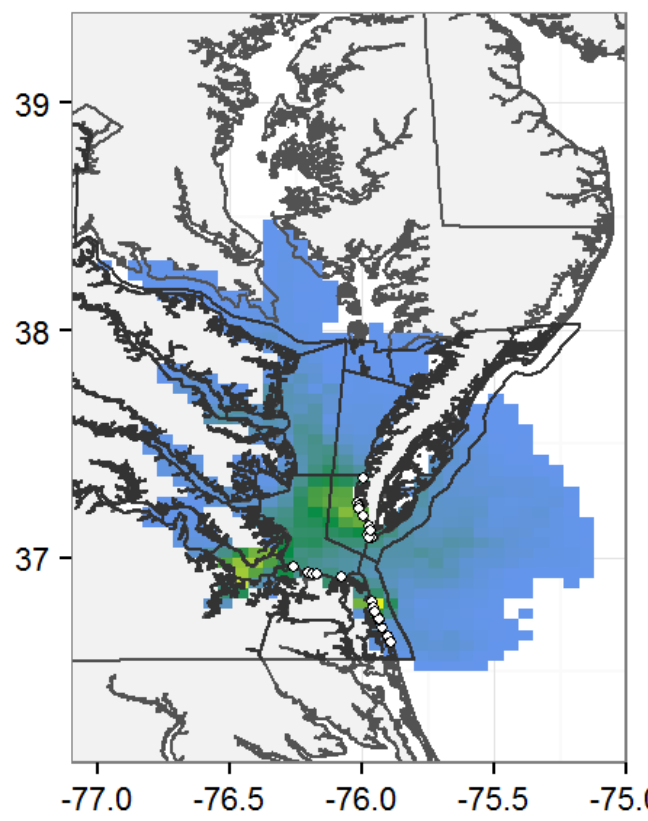

0.00 .51 .01 .52 .0 
1015 Figure 7

Probable Cause of Death: Unable to assess

(A) Spring Peak
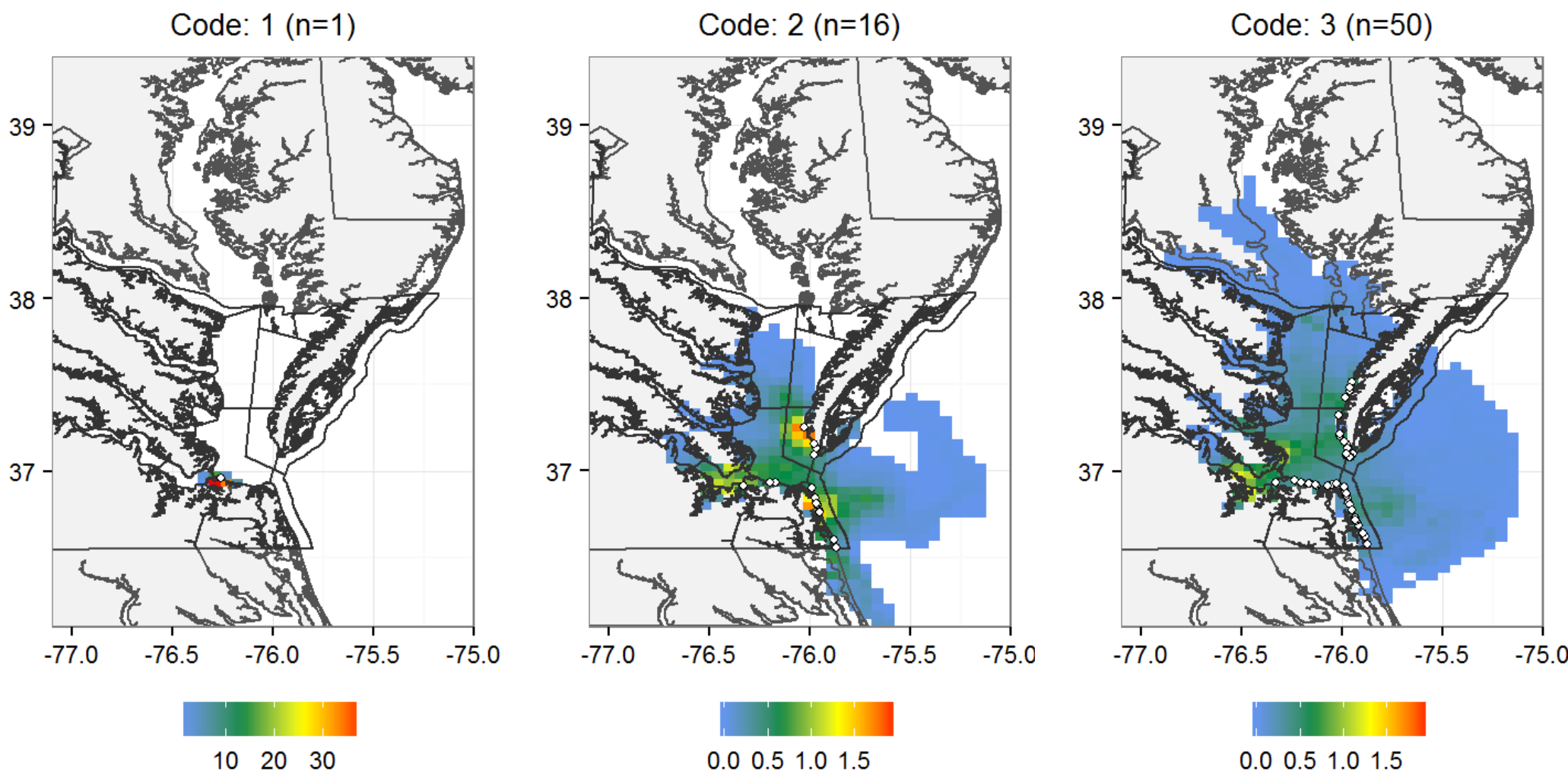

(B) Remaining stranding period Code: $2(n=38)$
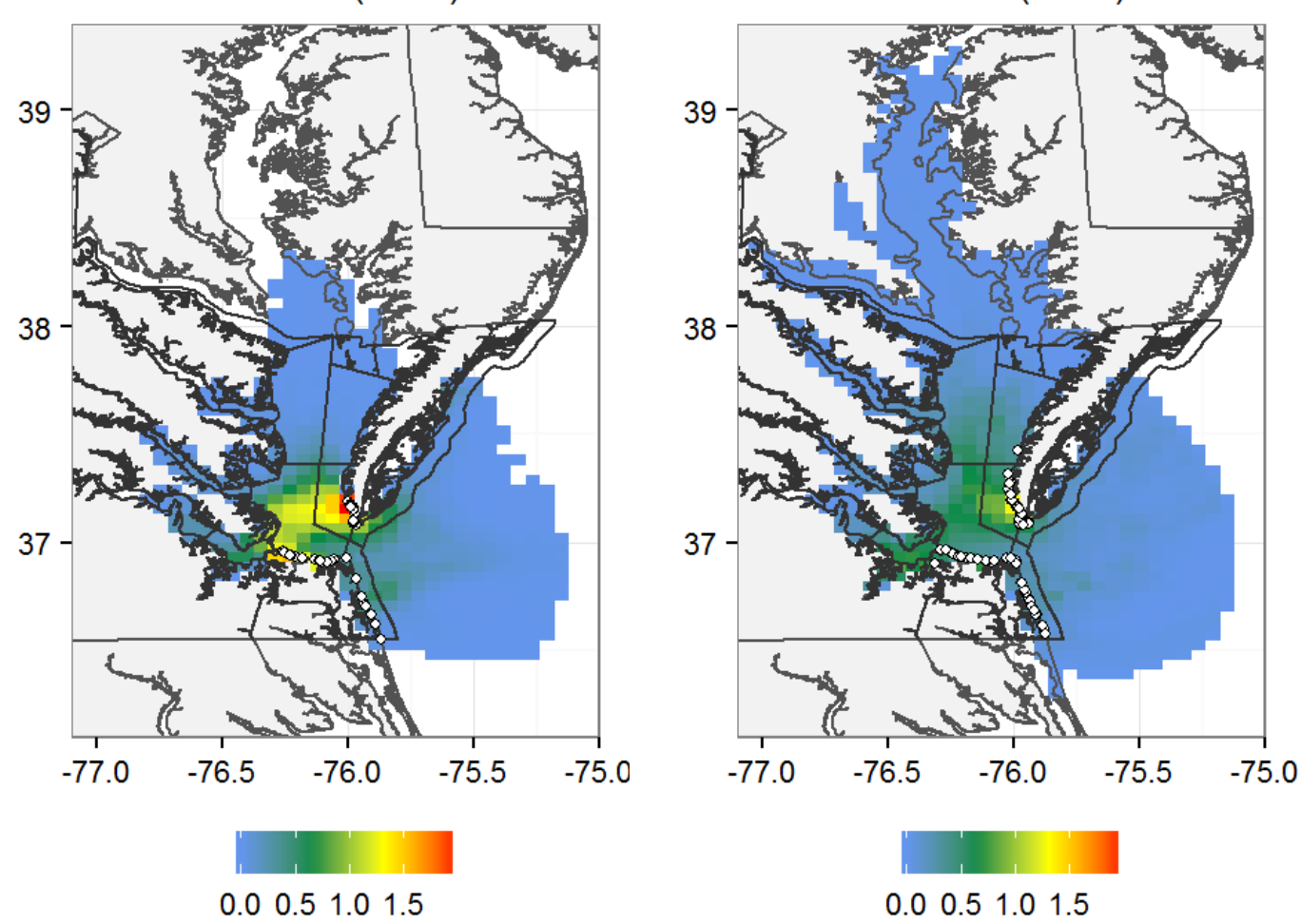
1016 Figure 8

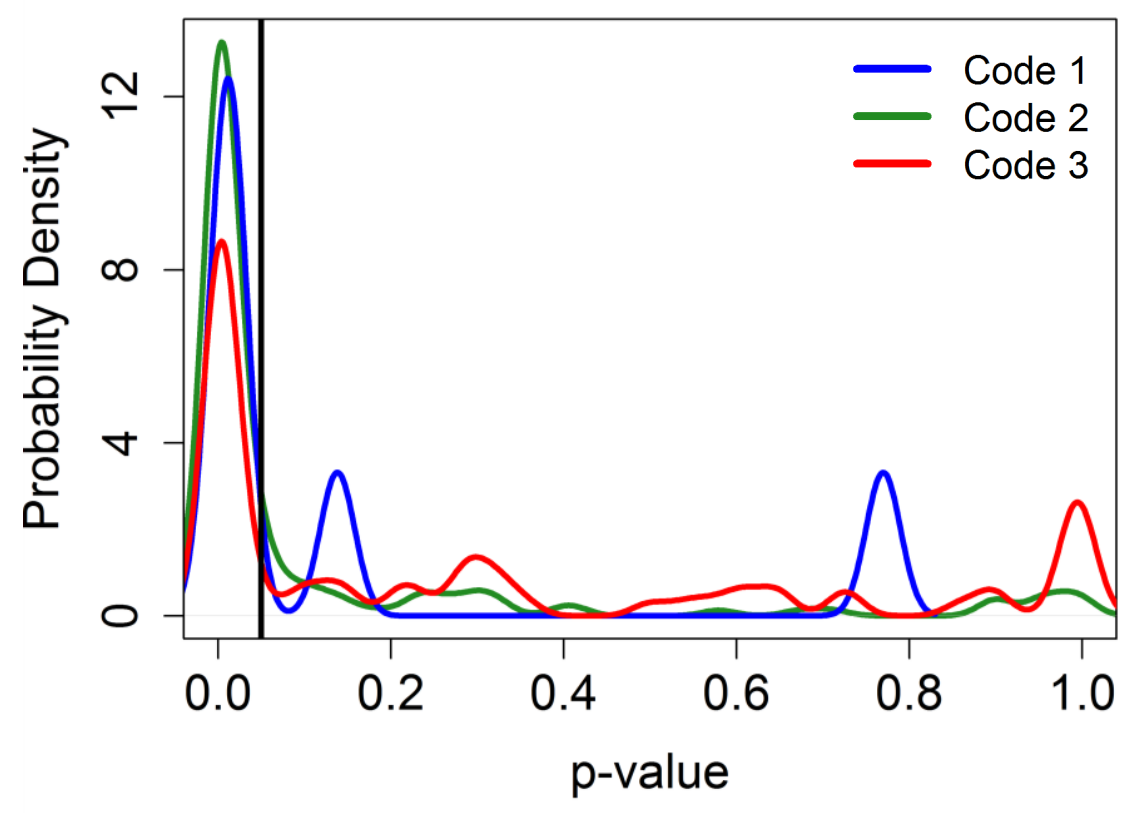


1017 Figure 9
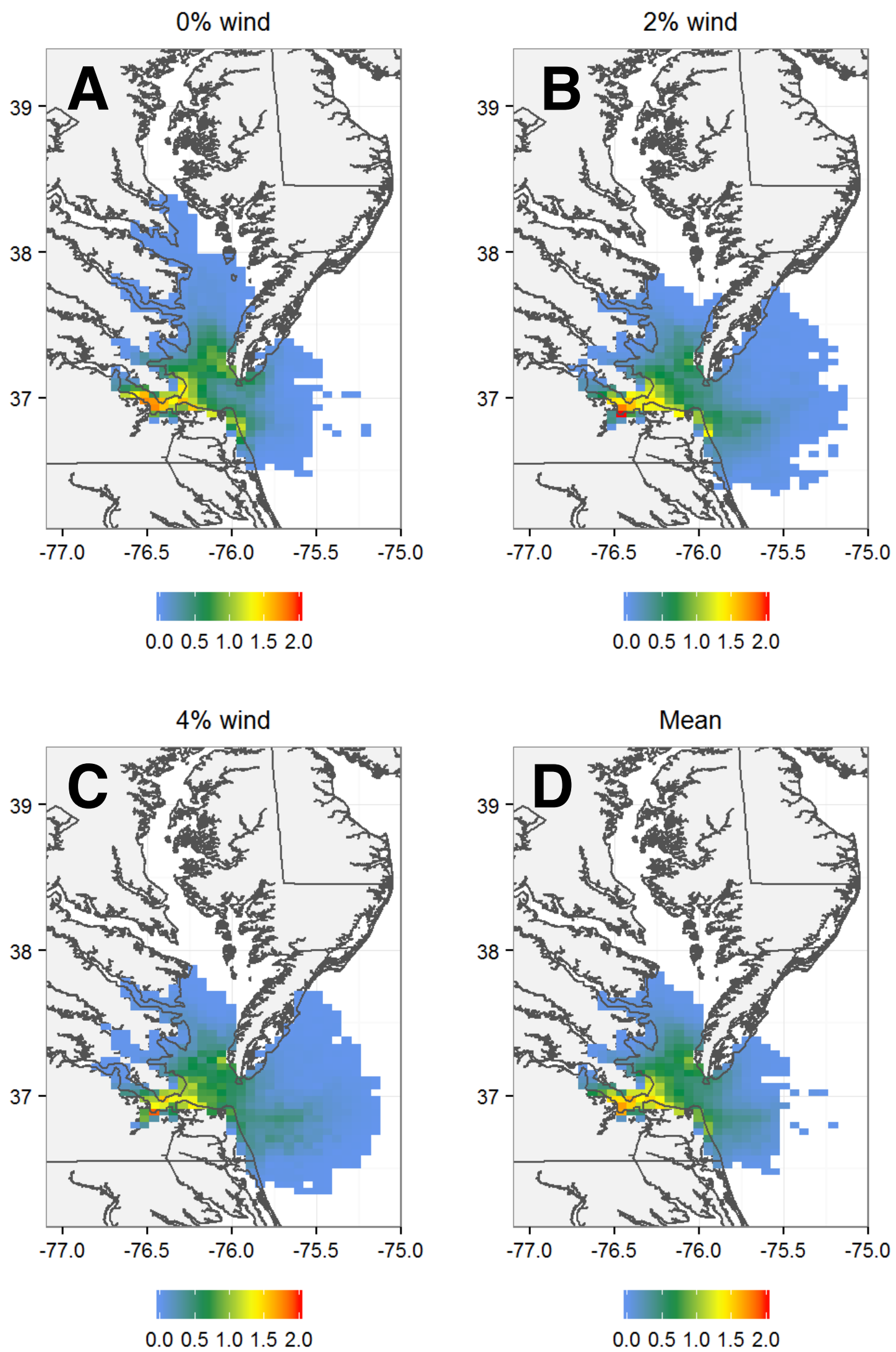
1018 Figure 10

Gillnets (drift)
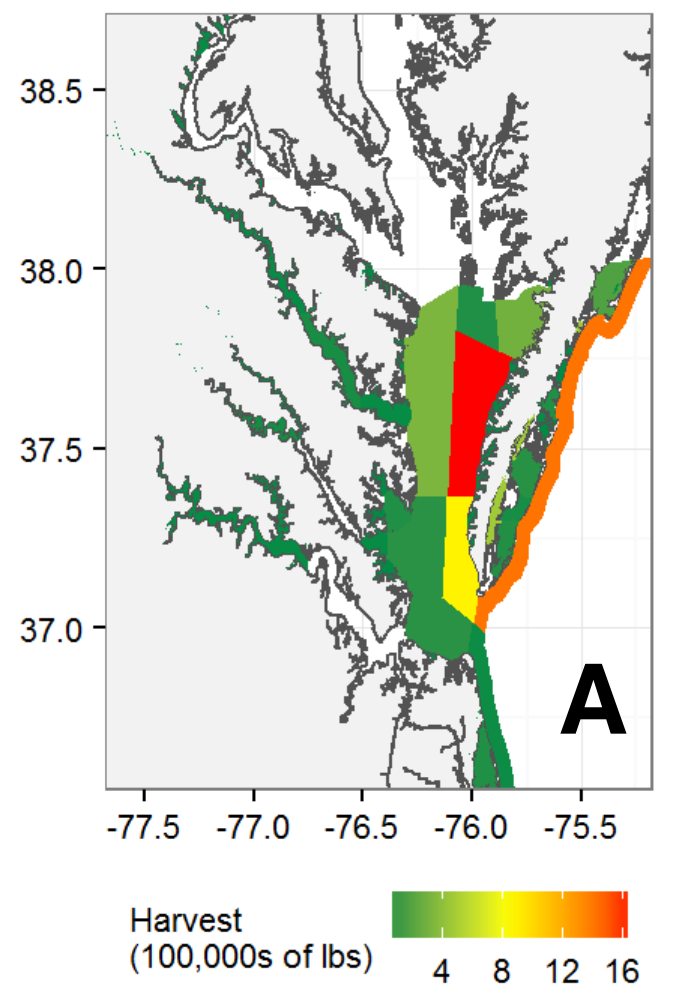

Gillnets (sink/anchor)

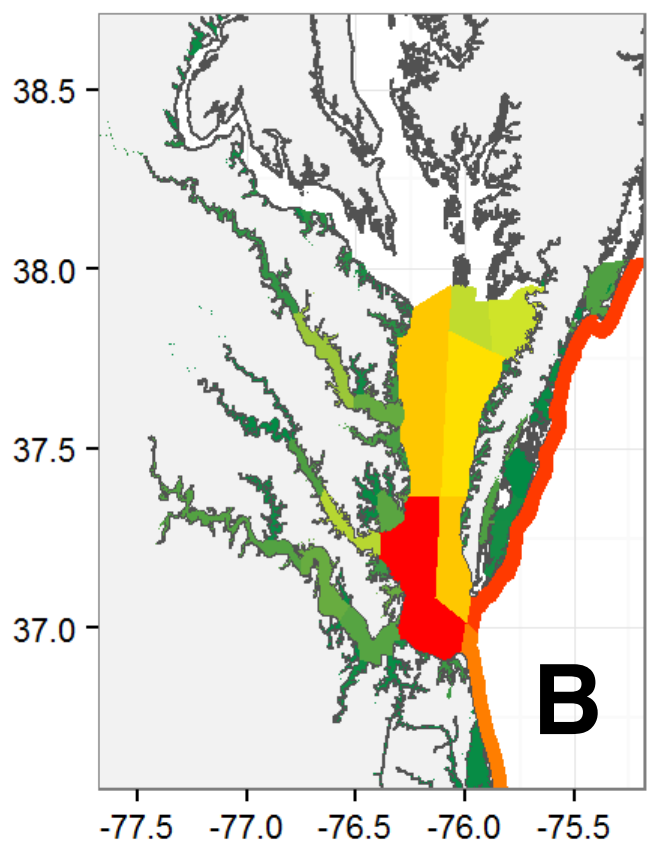

Harvest

$(100,000$ s of lbs $) \quad 20 \quad 40 \quad 60$
Haul Seine

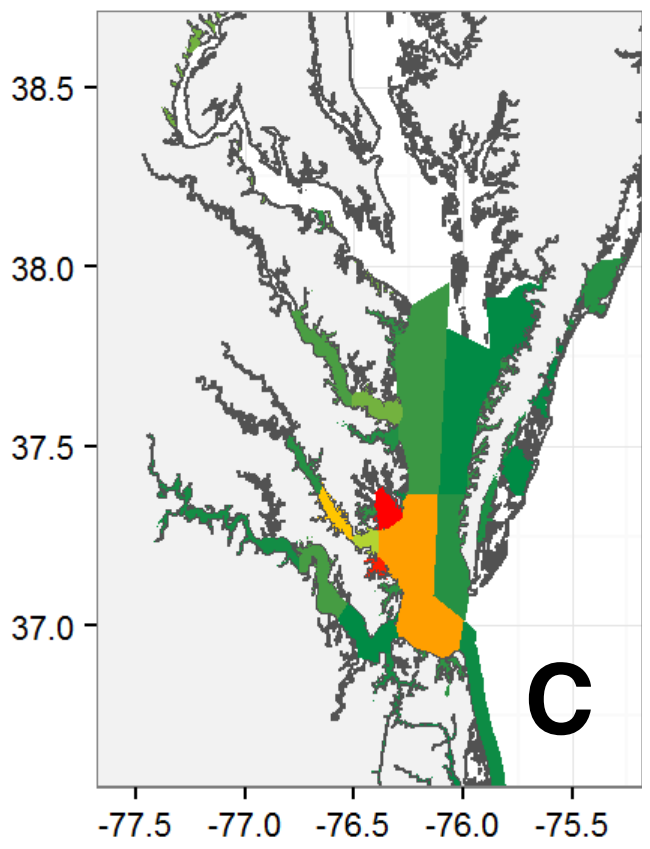

Harvest

$(100,000$ s of lbs $)$

5101520
Pots and Traps (whelk)

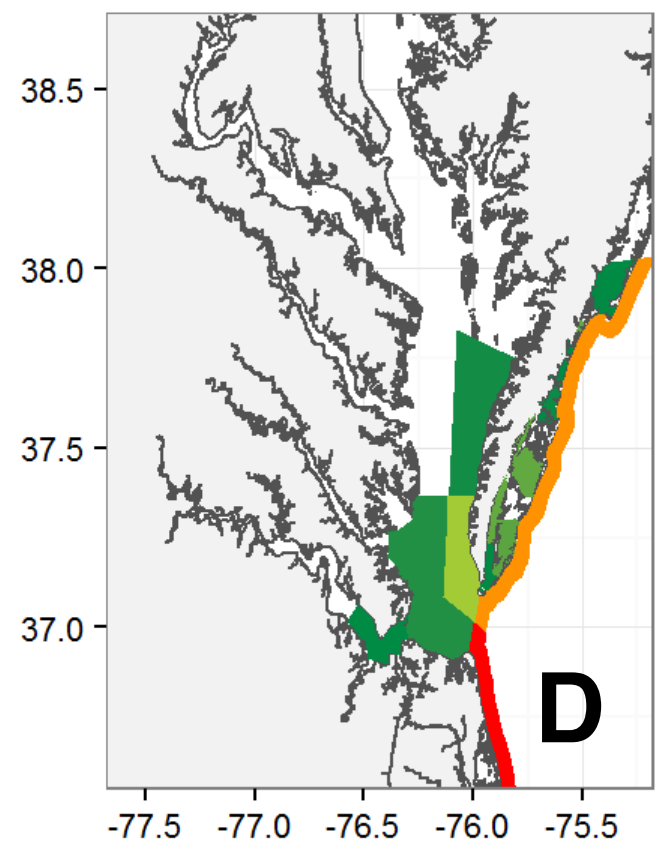

Harvest

$(100,000$ s of lbs $)$ $\begin{array}{llll}2 & 4 & 6 & 8\end{array}$
Pots and Traps (crab)

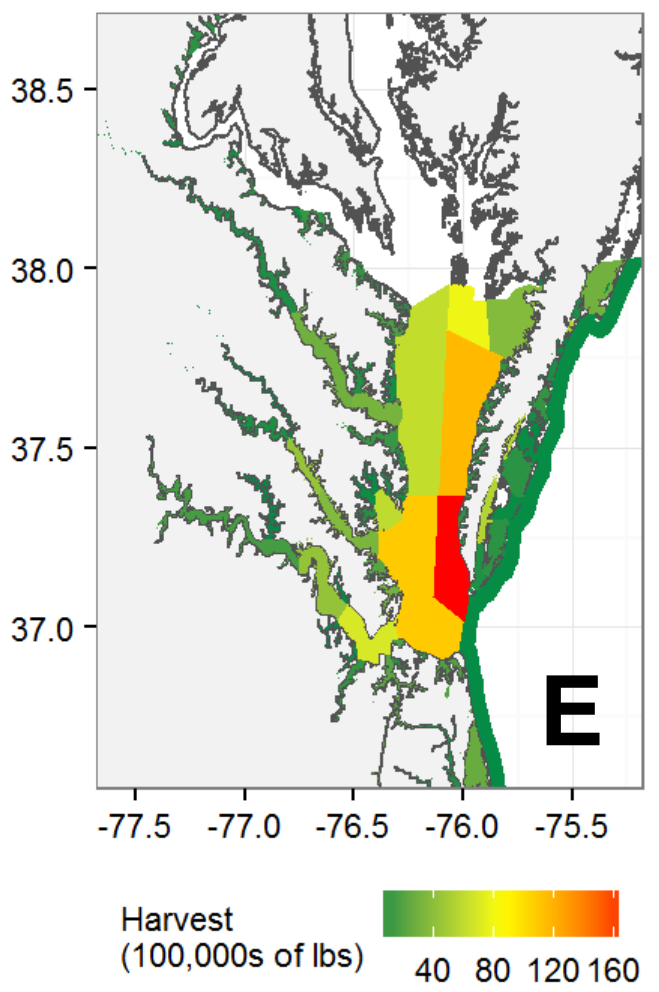


Figure 11
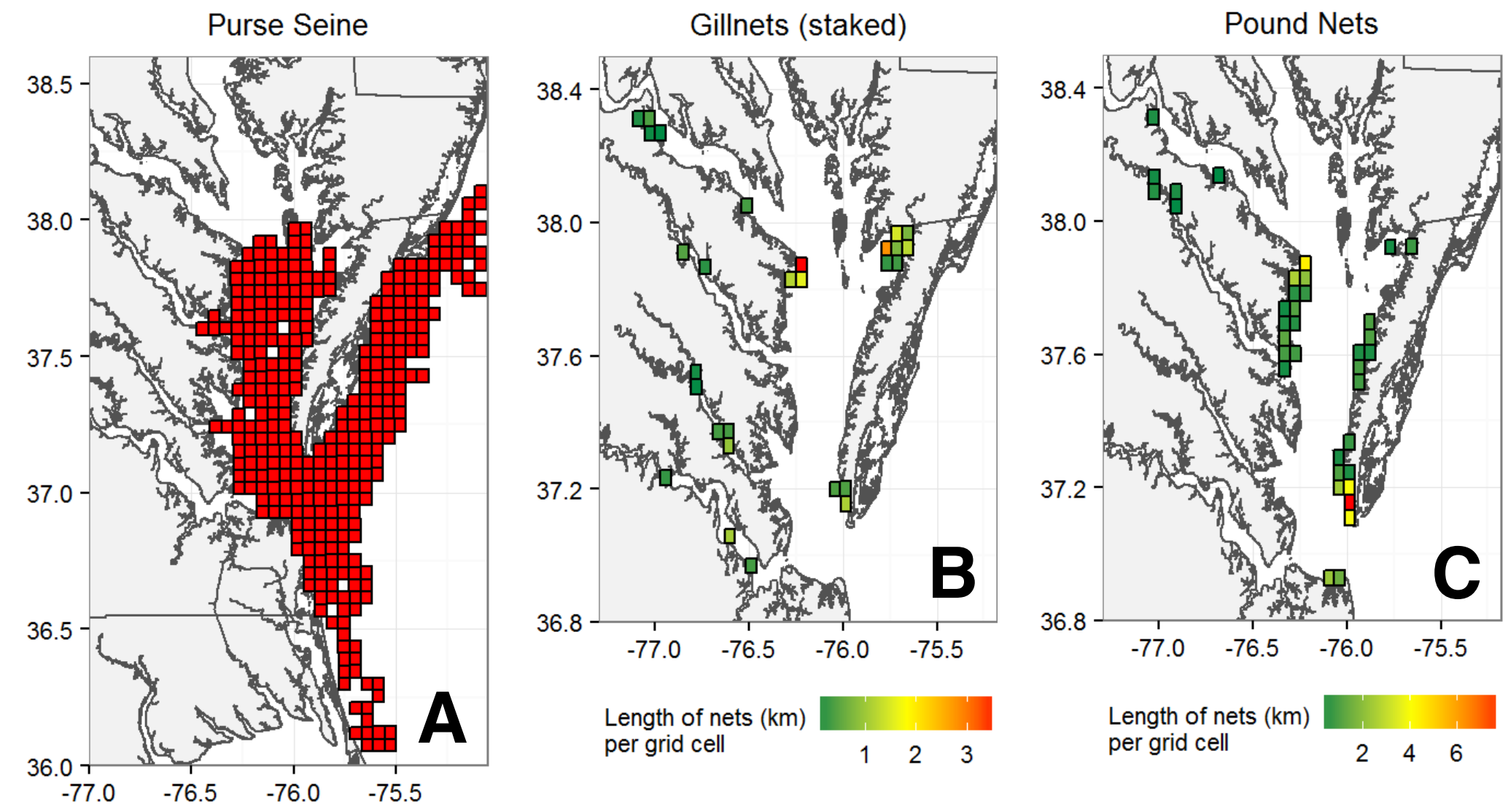
1020 Appendix

1021 Figure A.1. Frequency of all reported stranding events per week of the year for 2009-2014.

1022 Shaded areas represent the spring peak (red; 3-5 weeks) and the remainder of the

1023 stranding period (green; 19-23 weeks).

1024 Figure A.2. Virginia Marine Resource Commission waterways (black outline) and system (color) 1025 identification.

1026 Figure A.3. Harvest (hundreds of thousands of pounds) by (A) staked gillnet and (B) pound net 1027 gear. Data was obtained from the Virginia Marine Resource Commission and aggregated $1028 \quad$ over 2009-2014.

1029 
1032 Figure A.2

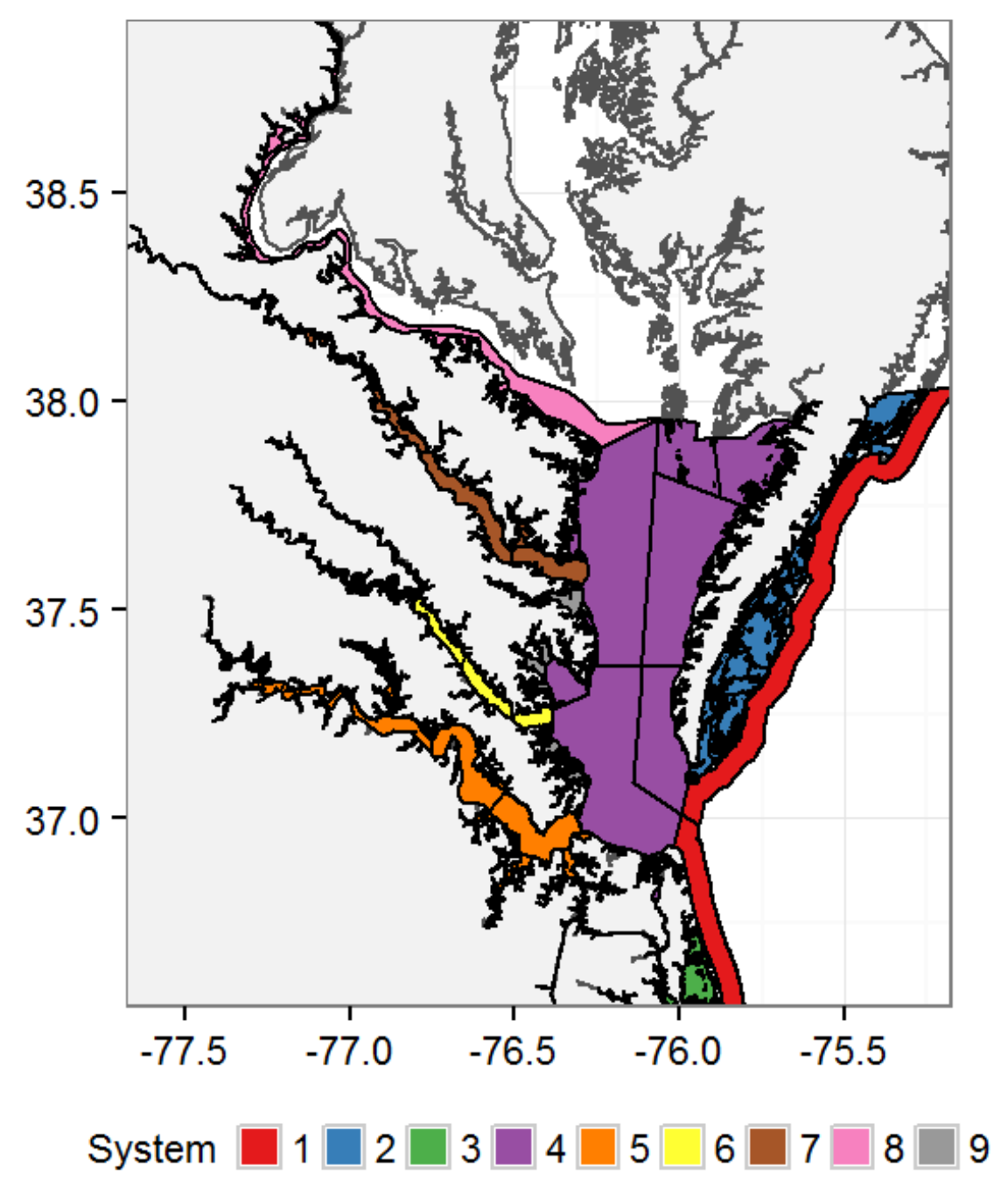


1033 Figure A.3

1034

1035

1036

1037

1038

1039

1040

1041

1042

1043

1044

1045

1046

1047

1048

1049

1050

1051

1052

1053

1054

1055
Gillnets (staked)

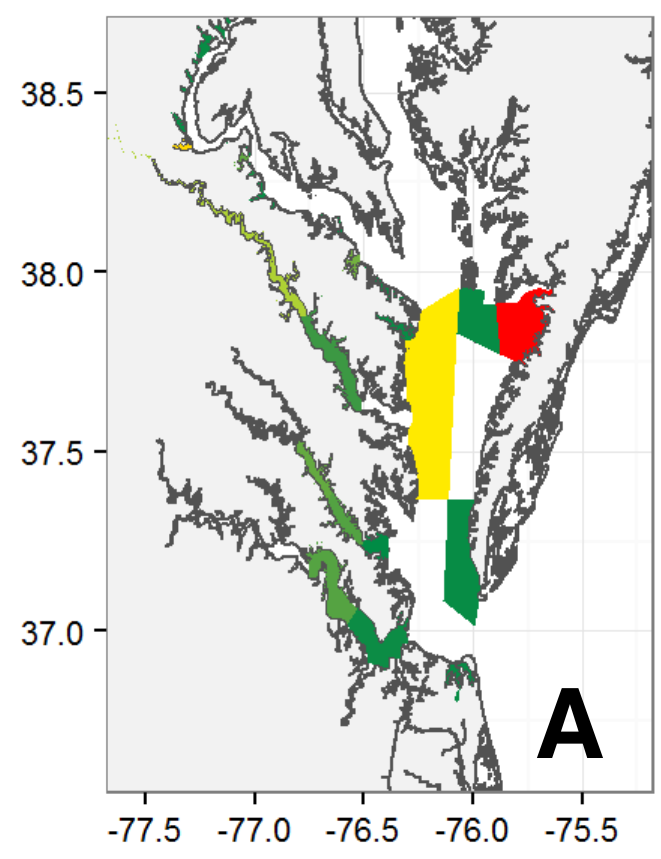

Harvest

$(100,000 \mathrm{~s}$ of lbs $)$

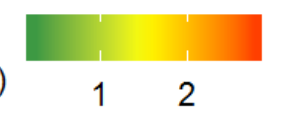

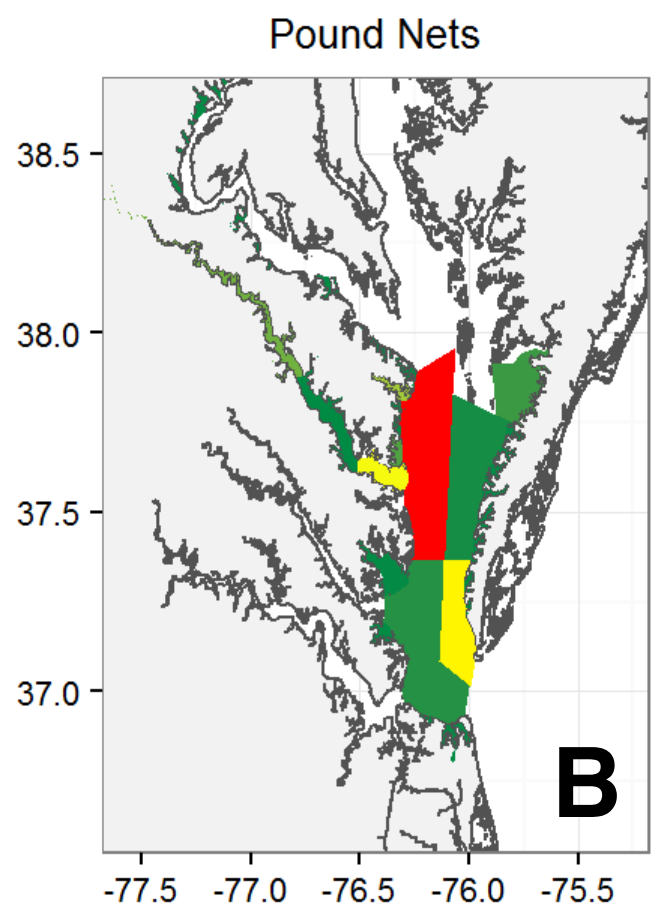

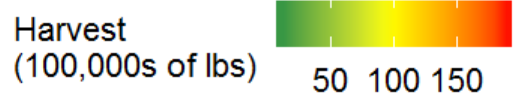




\section{Supplement materials}

\section{Drift simulations to compare drift trajectories from modelled pseudo-particles to experimentally-observed data}

Model simulations were performed using a "release stain" strategy in Ichthyop (Lett et al. 2008). Ten-thousand pseudo-particles were released in the ChesROMS model at the times of the releases of the pseudo-carcasses and buckets shown in Figure 6 of Santos et al. (2018). Particles werre released within a $3 \mathrm{~km}$ buffer of the release positions. Although ChesROMS model skill has not been previously demonstrated for surface velocities using drifters, it has undergone extensive skill assessment (Feng et al. 2015, Irby et al. 2016, Luettich et al. 2017, Moriarty 2017, Irby et al. 2018, Da 2018, Da et al. 2018). Furthermore, we note that the physical circulation is very well represented within the Bay, as is evidenced by the high skill of the model in reproducing observed salinity.

The movement of the pseudo-particles were tracked as they moved forward until the moment in time that the actual drifters beached. Drift trajectories of modeled pseudo-particles were compared to the drift pathways and stranding locations of the actual drifters. When comparing with the movements of the bucket drifters, no wind forcing was added to the ChesROMS currents, while in the case of the pseudo-carcasses, winds were added at $2 \%$ (the value closest to observed values in Santos et al. (2018) and the wind forcing that is (primarily) used in this study). Simulations were repeated for each of the four drifter deployments.

(1)


Wind Forcing: 0\% | Objects: Buckets
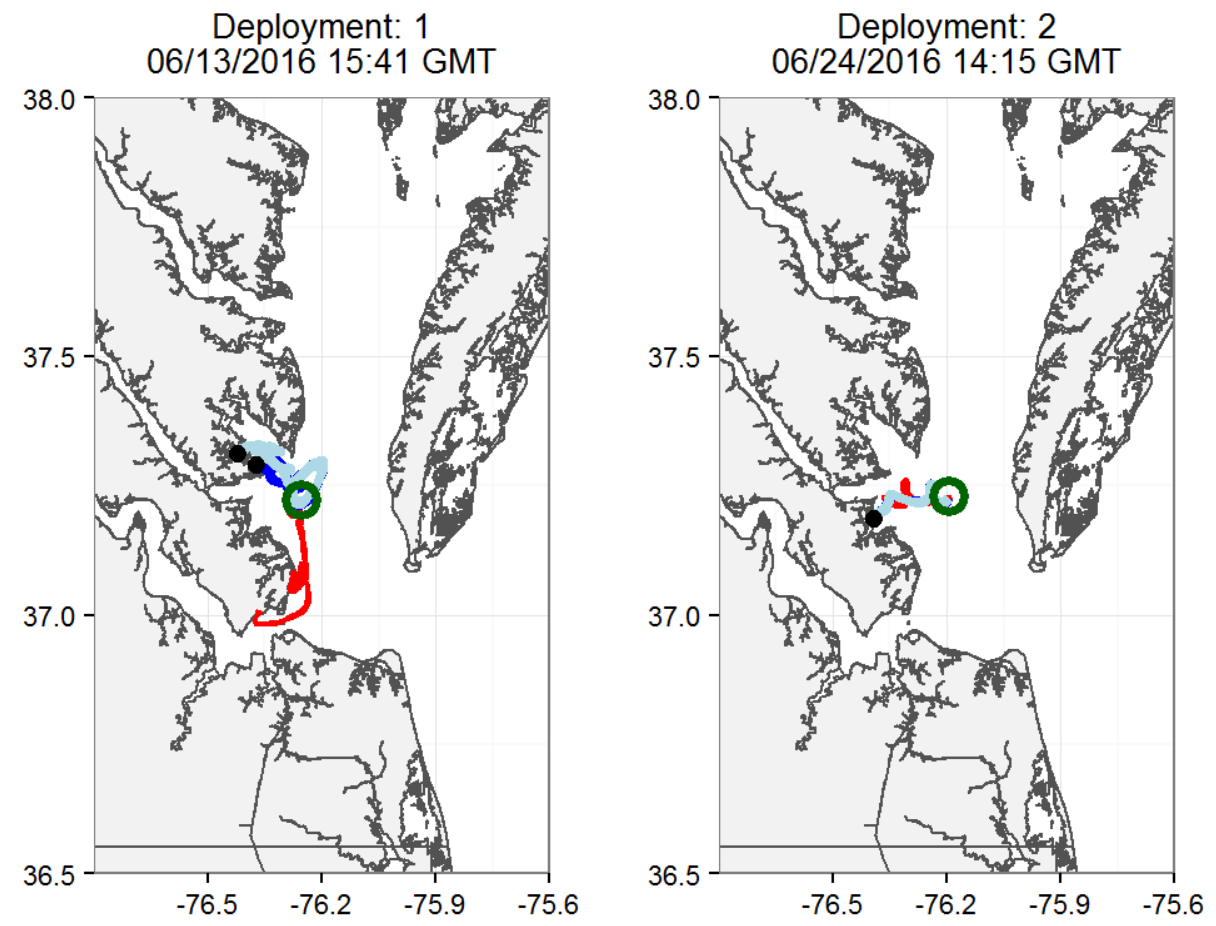

1083
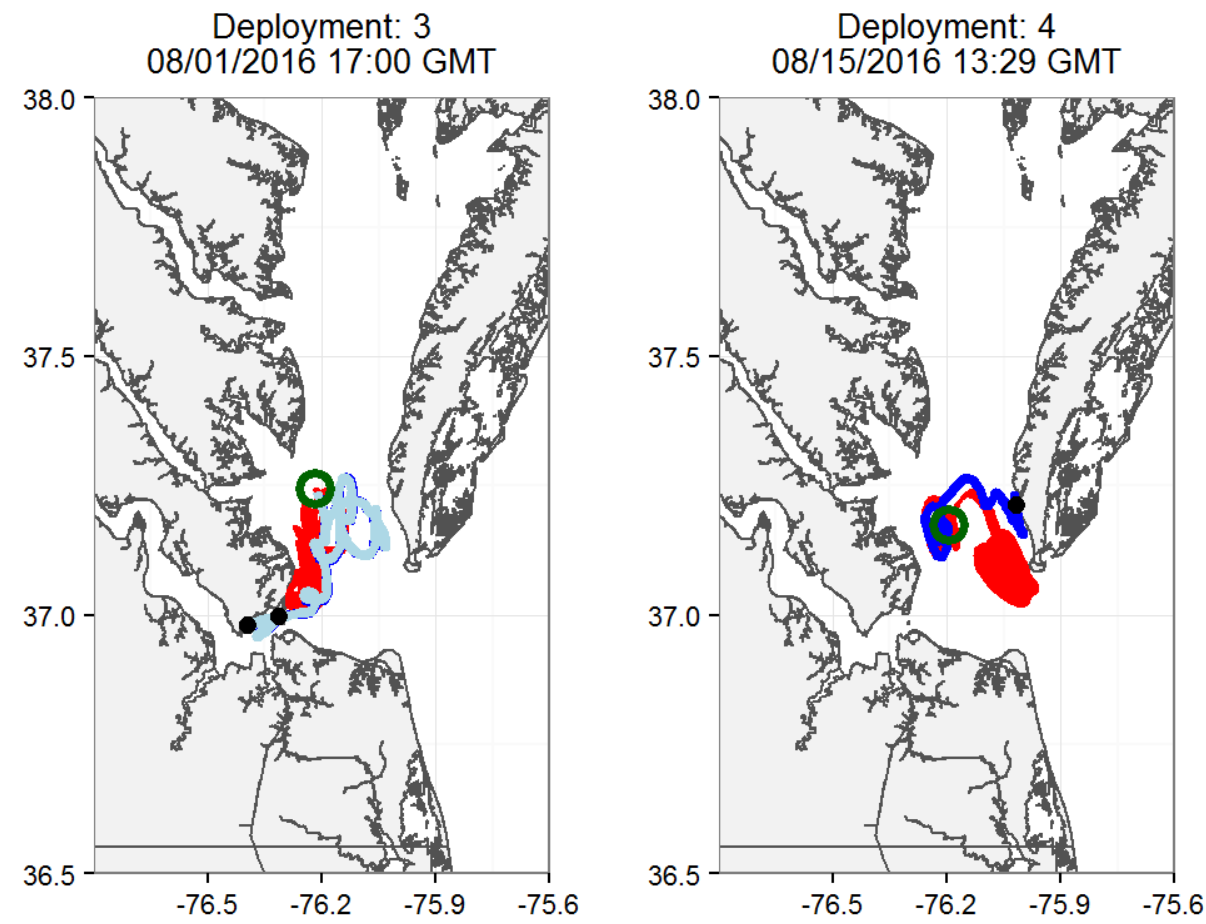

1084

1085

\section{Release stain trajectory} Bucket 1 trajectory Bucket 2 trajectory

- Location of deployment/simulation release

- Location of beached drifter 
Wind Forcing: 2\% | Objects: Pseudo-turtles
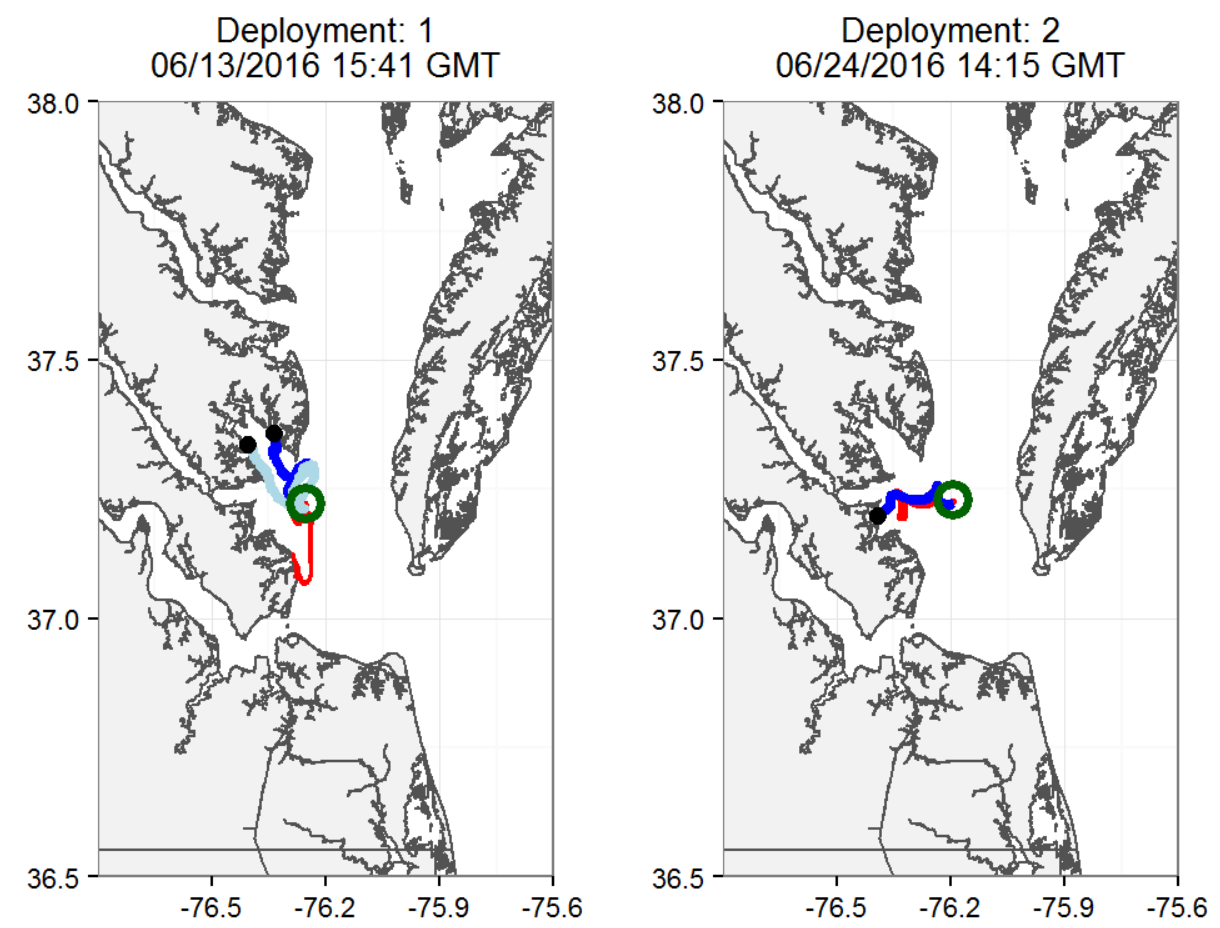

1086
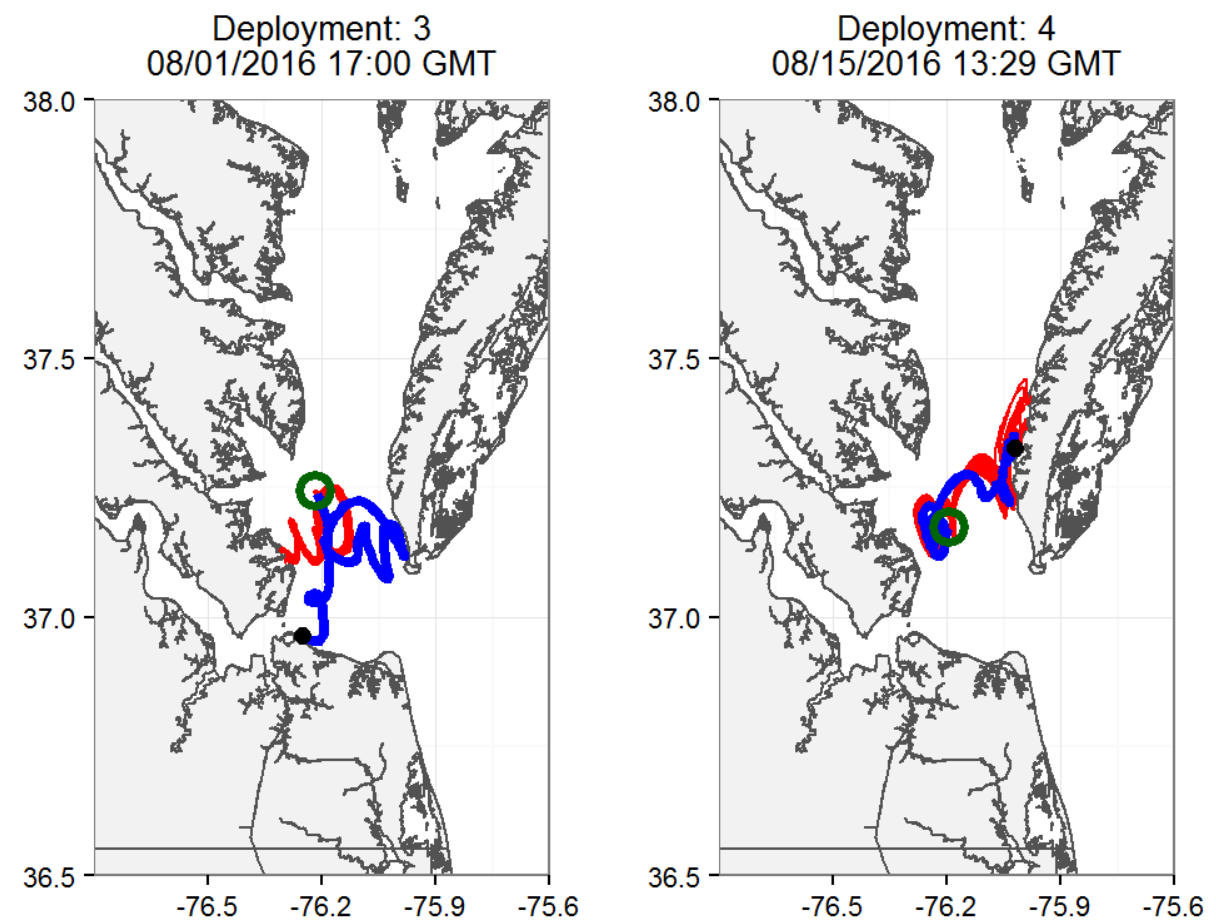

1087

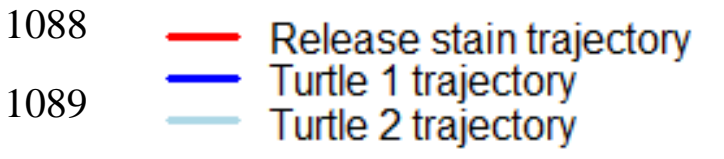

- Location of deployment/simulation release

- Location of beached drifter

1090 
Overall, results from the stain simulations compared well with actual drift trajectories.

1092 The particle tracks have the same overall form as the drift pathways of the objects, following the

1093 same tidal oscillations and overall direction of transport, and generally arriving close to the

1094 stranding area in three of the four deployments. However the model does miss some complexity

1095 in transport, particularly for Deployment 1 . The release time of deployment 1 occurred at

1096 approximately 15:41 GMT on June 13, 2016, right around the time that the tides in the area were

1097 turning after experiencing a high tide at 15:44 GMT, as reported by a nearby buoy (National

1098 Oceanographic and Atmospheric Administration’s Tidal Current Predictions

1099 (http://tidesandcurrents.noaa.gov/) for station ACT5406 York River Entrance Channel, NW end).

1100 It is possible that the close proximity of the drifter release to the changing of the tides could have 1101 caused some of the observed discrepancies between model results and drifter experiments for

1102 this release event. For real drifters released at essentially the same time and place, we observed

1103 relatively rapid separations between paired identical drifters during slack tides. The proximity of

1104 this release to changing tides combined with relatively small spatial or temporal misalignments

1105 between the model and real currents could therefore explain the observed discrepancies.

1106 To reduce the importance of poor alignment between the model and true current

1107 variability for any individual stranding, the approach followed in this paper have been to

1108 aggregate over many stranding events. We never present results for a single stranding or specific

1109 transport times, but instead look at averages over many events. It is also worthwhile to note that

1110 the coarse domain of the ChesROMS model may cause inaccurate simulation of particles in the

1111 coastal area. Using a model with higher horizontal resolution and/or an unstructured grid that

1112 better represents the complex coastline, such as the Semi-implicit Cross-scale Hydroscience 
1113 Integrated System Model (Ye et al. 2016, 2018), is an important avenue for future improvement 1114 to our model

1115 References

1116 Da, F. 2018. Impacts of Direct Atmospheric Nitrogen Deposition and Coastal Nitrogen Fluxes on 1117 Chesapeake Hypoxia. MS Thesis, Virginia Institute of Marine Science, College of 1118 William \& Mary.

1119 Da, F., M.A.M. Friedrichs, P. St-Laurent, 2018. Impacts of atmospheric nitrogen deposition and 1120 coastal nitrogen fluxes on Chesapeake Bay hypoxia, Journal of Geophysical Research: $1121 \quad$ Oceans, in minor revision.

1122 Feng, Y., M. A. M. Friedrichs, J. Wilkin, H. Tian, Q. Yang, E. E. Hofmann, J. D. Wiggert, and 1123 R. R. Hood. 2015. Chesapeake Bay nitrogen fluxes derived from a land-estuarine ocean 1124 biogeochemical modeling system: Model description, evaluation, and nitrogen budgets. 1125 Journal of Geophysical Research: Biogeosciences 120:1666-1695.

1126 Irby, I. D., M. A. M. Friedrichs, C. T. Friedrichs, A. J. Bever, R. R. Hood, L. W. J. Lanerolle, M. 1127 Li, L. Linker, M. E. Scully, K. Sellner, J. Shen, J. Testa, H. Wang, P. Wang, and M. Xia. 1128 2016. Challenges associated with modeling low-oxygen waters in Chesapeake Bay: A 1129 multiple model comparison. Biogeosciences 13:2011-2028.

1130 Irby, I.D., M.A.M. Friedrichs, F. Da and K. Hinson, 2018. The competing impacts of climate 1131 change and nutrient reductions on dissolved oxygen in Chesapeake Bay. Biogeosciences, 1132 15, 2649-2668, doi.org/10.5194/bg-15-2649-2018. 
1133 Lett, C., P. Verley, C. Mullon, C. Parada, T. Brochier, P. Penven, and B. Blanke. 2008. A

1134 Lagrangian tool for modelling ichthyoplankton dynamics. Environmental Modelling \& $1135 \quad$ Software 23:1210-1214.

1136 Luettich, R.A., L.D. Wright, C.R. Nichols, R. Baltes, M.A.M. Friedrichs, A. Kurapov, A.J. van 1137 der Westhuysen, K. Fennel and E. Howlett, 2017. A U.S Integrated Ocean Observing 1138 System Coastal and Ocean Modeling Testbed to improve understanding and operational 1139 forecasts of extreme events and chronic environmental conditions, Eos, 98, $1140 \quad$ doi.org/10.1029/2017EO078243.

1141 Moriarty, J. M. 2017. The Role of Seabed Resuspension on Oxygen and Nutrient Dynamics in 1142 Coastal Systems: A Numerical Modeling Study. PhD Dissertation, Virginia Institute of 1143 Marine Science, College of William \& Mary.

1144 Santos, B. S., D. M. Kaplan, M. A. M. Friedrichs, S. G. Barco, K. L. Mansfield, and J. P. 1145 Manning. 2018. Consequences of drift and carcass decomposition for estimating sea 1146 turtle mortality hotspots. Ecological Indicators 84:319-336.

1147 Ye, F., Y. J. Zhang, M. A. M. Friedrichs, H. V. Wang, I. D. Irby, J. Shen, and Z. Wang. 2016. A 1148 3D, cross-scale, baroclinic model with implicit vertical transport for the Upper 1149 Chesapeake Bay and its tributaries. Ocean Modelling.

1150 Ye, F., Y. J. Zhang, H. V. Wang, M. A. M. Friedrichs, I. D. Irby, E. Alteljevich, A. Valle1151 Levinson, Z. Wang, H. Huang, J. Shen, and J. Du. 2018. A 3D unstructured-grid model 1152 for Chesapeake Bay: importance of bathymetry. Ocean Modelling. 